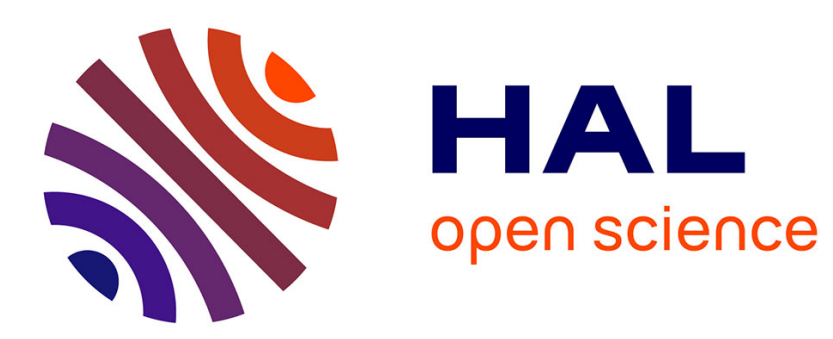

\title{
Pay less, consume more? The price elasticity of home care of the disabled elderly in France
}

\author{
Quitterie Roquebert, Marianne Tenand
}

\section{To cite this version:}

Quitterie Roquebert, Marianne Tenand. Pay less, consume more? The price elasticity of home care of the disabled elderly in France. Health Economics, 2017, 10.1002/hec.3531 . hal-01385678v2

\section{HAL Id: hal-01385678 \\ https://hal.science/hal-01385678v2}

Submitted on 24 Sep 2019

HAL is a multi-disciplinary open access archive for the deposit and dissemination of scientific research documents, whether they are published or not. The documents may come from teaching and research institutions in France or abroad, or from public or private research centers.
L'archive ouverte pluridisciplinaire HAL, est destinée au dépôt et à la diffusion de documents scientifiques de niveau recherche, publiés ou non, émanant des établissements d'enseignement et de recherche français ou étrangers, des laboratoires publics ou privés. 


\title{
Pay less, consume more? \\ The price elasticity of home care for the disabled elderly in France
}

Quitterie Roquebert* and Marianne Tenand ${ }^{\dagger}$

Post-print of the paper:

Roquebert, Quitterie and Marianne Tenand. 2017. "Pay Less, Consume

More? The Price Elasticity of Home Care for the Disabled Elderly in

France". Health Economics 26(9):1162-74. https://doi.org/10.1002/hec.3531

This document includes the Appendices provided as Online Supplementary Materials.

\begin{abstract}
Little is known about the price sensitivity of demand for home care of the disabled elderly. We partially fill this knowledge gap by using administrative data on the beneficiaries of the main French home care subsidy program in a department and exploiting inter - individual variation in provider prices. We address the potential endogeneity of prices by taking advantage of the unequal spatial coverage of providers and instrumenting price by the number of municipalities served by a provider. We estimate a price elasticity of around -0.4 that is significantly different from both 0 and -1 . This less than proportionate response of consumption to price has implications for the efficiency and redistributive impact of variation in the level of co-payments in home care subsidy schemes.
\end{abstract}

JEL Classification: C24; D12; I18; J14.

Keywords: Long-term care, home care, disabled elderly, price elasticity, censored regression.

\footnotetext{
*Paris School of Economics, Université Paris 1. E-mail: quitterie.roquebert@univ-paris1.fr

$\dagger$ Paris School of Economics, Ecole normale supérieure, Paris Sciences et Lettres. E-mail: marianne.tenand@ens.fr
} 


\section{Acknowledgments}

We are grateful to an anonymous French Departmental Council (Conseil départemental) for granting access to its files. Access to survey Vie quotidienne et santé (VQS) was granted by Réseau Quételet. Information about funding to be found at the end of the paper. We are grateful to the MODAPA research team for fruitful discussions and especially to Agnès Gramain, Cécile Bourreau-Dubois and Helen Lim for their many comments. We would like to express our gratitude to Isaac Barker, Thomas Barnay, Matthieu Cassou, Fabrice Etilé, Amy Finkelstein, Pierre-Yves Geoffard, Michael Gerfin, Camille Hémet, Helena Hernández-Pizarro, Philipp Ketz, André Masson, Julien Mousquès, Simon Rabaté, Lise Rochaix, Nicolas Sirven, Jérôme Wittwer as well as to two anonymous Referees and the editorial committee of this journal, for their critical reading and suggestions. This paper also benefited from valuable feedback from the participants of various seminars (at Hospinnomics, PSE, Liraes and Ined) and several conferences (2016 edition of JESF, CDC Scientific Seminar on Pensions and Ageing, ILPN Conference, European Workshop on Econometrics and Health Economics, EuHEA Conference, HESG Summer Conference, AFSE Annual Meeting and JMA). All remaining errors are ours.

\section{Funding information}

This research was carried out within the MODAPA project (www.modapa. cnrs.fr). Funding comes from Agence nationale de la recherche (ANR-14CE30-0008) and from the joint support of Direction Générale de la Santé (DGS), Mission recherche de la Direction de la recherche, des études, de l'évaluation et des statistiques (MiRe-DREES), Caisse Nationale d'Assurance Maladie des Travailleurs Salariés (CNAMTS), Régime Social des Indépendants (RSI) and Caisse Nationale de Solidarité pour l'Autonomie (CNSA), through the call for projets launched by the Institut de recherche en santé publique (IRESP) in 2013. 


\section{INTRODUCTION}

Like most developed countries, France is facing the ageing of its population: due to the increase in life expectancy and the advance in age of baby-boomers, the share of the population above 75 is predicted to grow from $9.0 \%$ in 2013 to $17.2 \%$ in 2060 (Blanpain and Buisson, 2016). As the rise in disability-free life expectancy falls short of the increase in life expectancy (Sieurin et al., 2011), the number of the elderly needing assistance to perform the activities of daily living is expected to grow substantially. Most disabled elderly keep on living in the community rather than entering specialized institutions (Colombo et al., 2011). Besides medical and nursing care, they are often provided with domestic help and personal care. Assistance may be provided by relatives (informal care) and also by professional services (formal care), whose utilization is increasing. In most countries, public policies foster the utilization of formal home care by subsidizing its consumption. These programs, however, only partially cover the cost of professional home care and the disabled elderly often bear non-negligible out-of-pocket (OOP) costs. In France, the average monthly OOP payment for home care was estimated to be $€ 300$ in 2011 (Fizzala, 2016); over one fifth of the average pension (Solard, 2015).

We address the following question: how sensitive to price are the disabled elderly when consuming professional home care? Besides concerns regarding the financial accessibility of long-term care services, OOP payments raise efficiency issues. As in the health care context, generous home care subsidies may induce over-consumption and a welfare loss, while insufficient coverage could have adverse health effects (Stabile et al., 2006; Rapp et al., 2015; Barnay and Juin, 2016) or induce beneficiaries to substitute home care for more expensive institutional care (Ettner, 1994; Guo et al., 2015). Uncovering the impact of OOP price on home care consumption is crucial to design an optimal subsidy policy that would achieve ex ante insurance of uncertain LTC costs while limiting ex post demand-side moral hazard (Zeckhauser, 1970; Cutler and Zeckhauser, 2000; Bakx et al., 2015). Our paper brings evidence on this empirical question by estimating the price elasticity of the demand for nonmedical home care services of the disabled elderly, at the intensive margin.

We focus on the French home care scheme targeted to the disabled elderly, the APA (Allocation personnalisée d'autonomie) policy, which counted 738,000 community-dwelling beneficiaries in 2014 and amounted to a spend- 
ing of 3.1 billion euros in 2013 (0.15\% of GDP). ${ }^{1}$ Administrative records of the scheme provide detailed information on home care consumption and OOP payments of APA beneficiaries but they are available only at the local level. We use an original dataset made of the individual records we collected for the beneficiaries of a given Departmental Council (Conseil départemental). We exploit inter-individual variations in provider prices to identify consumer price elasticity. Price endogeneity may arise if APA beneficiaries non-randomly choose their home care provider. To address this issue, we exploit the unequal spatial coverage by providers in the department. We fit a censored regression model to deal with observational issues and control for disposable income and other individual characteristics likely to affect the consumption of home care.

Our results indicate a negative price elasticity, with point estimates ranging from -0.5 to -0.1 . According to our favoured estimation, an increase of $10 \%$ of the hourly OOP price would reduce total hours consumed by $4 \%$ on average, or 70 minutes per month for a beneficiary consuming the median monthly volume of 18 hours. Although confidence intervals are relatively large, we statistically reject a price elasticity of both 0 and -1 in most specifications.

Our paper provides one of the very first estimates of the price elasticity of the demand for home care services of the disabled elderly. Despite the growing concern about the financing of long-term care, the impact of OOP payments on the consumption of home care has been little investigated in the economic literature. A few papers tested for the effect of benefiting from subsidies on the utilization of paid home care (Coughlin et al., 1992; Ettner, 1994; Pezzin et al., 1996; Stabile et al., 2006; Rapp et al., 2011; Fontaine, 2012); because of data limitations, they were not able to quantify the price sensitivity. To our knowledge, the only existing studies addressing this gap in the literature exploit French data. Using national survey data, Hege (2016) makes assumptions on unobserved OOP prices and estimates a price elasticity of -0.16 . Bourreau-Dubois et al. (2014) use APA records from a department to observe exact home care prices, as we do, and estimate an elasticity of -0.55 . We use a different, original dataset and propose an instrumental variable strategy to deal with potential price endogeneity.

Our results entail important policy implications, as home care subsidy schemes are expanding with population ageing. Home care consumption is found to be price sensitive, meaning that home care support programs have efficiency implications. Moreover, since consumption of home care reacts less

\footnotetext{
${ }^{1}$ Drees $(2013,2014)$. The APA program also has a component for the elderly living in nursing homes.
} 
than proportionately to a price change, home care subsidies should be regarded as a tool to achieve redistribution from taxpayers to the disabled elderly and reduce OOP spending on long-term care.

\section{INSTITUTIONAL CONTEXT AND DE- MAND FOR HOME CARE}

\subsection{The APA program}

The French APA program aims at fostering the utilization of professional care services by the elderly requiring assistance in the activities of daily living (household chores, meal preparation or personal hygiene). The APA policy is established at the national level and implemented at the departmental level. ${ }^{2}$ To be eligible, an individual must be at least 60 years-old and recognized as disabled. This second condition requires a specific assessment from a team managed by the Departmental Council, called the evaluation team, made of medical professionals (nurses, doctors) and/or social workers. The evaluation team visits each APA applicant to evaluate her needs of assistance using a national standardized scale. The applicant is thus assigned a disability group (Groupe Iso-Ressources, or GIR). Individuals found to be moderately (GIR-4) to extremely disabled (GIR-1) are eligible for APA, while the least severely disabled (GIR-5 or -6) are not.

The evaluation team then establishes a "personalized care plan". This document lists the activities for which the individual needs assistance and sets the number of hours necessary to their realization. It gives the maximum number of hours eligible for APA subsidies of each beneficiary, called the care plan volume. $^{3}$ Up to the care plan volume, the OOP price of each hour of care is lowered by the APA subsidy. The beneficiary is free to consume hours beyond the care plan volume but there are no more subsidies.

\subsection{Computation rules of APA subsidies}

For subsidized hours, the APA beneficiary is charged an hourly OOP price that depends on both the provider price and a co-payment rate, increasing

\footnotetext{
${ }^{2}$ Metropolitan France is divided into 95 departments.

${ }^{3}$ The monetary valuation of the care plan volume must not exceed a legal ceiling, which depends on the disability level. At the end of 2014, the ceiling was $€ 1,313$ (resp. €563) per month for GIR-1 (resp. GIR-4). Appendix D provides more elements on the set up of the care plan volume.
} 
with disposable income. For low-income individuals (below $€ 739$ per month at the end of 2014) the co-payment rate is zero, while it reaches $90 \%$ for the richest beneficiaries (monthly income above $€ 2,945$ ). In between the two, the co-payment rate is an increasing linear function of disposable income. ${ }^{4}$

If the provider chosen by the beneficiary is authorized, then the hourly OOP price is given by applying the co-payment rate to the regulated price charged by the provider. ${ }^{5}$ For "non-authorized" providers ${ }^{6}$ the co-payment rate is applied to a lump-sum price to get the OOP price. This distinction has important implications for what can be known of beneficiaries' OOP payments, since Departmental Councils usually keep track only of the prices of authorized providers.

\subsection{Modeling demand for home care with APA}

We write the Marshallian demand for professional home care assuming a heterogeneity-only model (Moffitt, 1986):

$$
h_{i}^{*}=g\left(C P_{i}, \hat{I}_{i} ; X_{i}\right)+\nu_{i}
$$

where $h_{i}^{*}$ is the number of hours of home care consumed by individual $i$ and $g($.$) denotes the demand function. Care consumption depends on the$ consumer (or OOP) price for one hour of home care, $C P_{i}$, on the total disposable income available for consumption $\hat{I}_{i}$, and on individual socio-demographic characteristics, $X_{i} . \nu_{i}$ is an individual preference shifter.

With APA, up to the care plan volume denoted $\bar{h}_{i}$, the hours consumed are subsidized. The consumer price is $C P_{i}=c\left(I_{i}\right) p_{i}$, where $p_{i}$ is the provider price for individual $i$ and the co-payment rate $c_{i}$ is a function of individual $i$ 's monetary disposable income: $c_{i}=c\left(I_{i}\right)$, with $c($.$) a linear function.$

Beyond the care plan volume $\bar{h}_{i}$, the consumer price equals the full provider price as there is no APA subsidy any more. The budget constraint is:

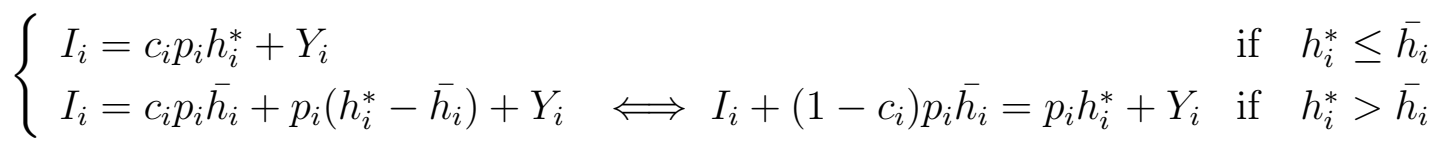

\footnotetext{
${ }^{4}$ The schedule of APA co-payments was substantially reformed in 2016 . We describe the pre-reform schedule.

${ }^{5} 49$ metropolitan Departmental Councils out of the 73 that answered a national survey conducted in 2012 applied this computation rule (LEDa-LEGOS and CES, 2012; Bourreau-Dubois et al., 2015). Authorized providers are generally priced by the Departmental Councils.

${ }^{6}$ It can be either a non-authorized structure (service agréé non-autorisé) or an over-the-counter worker (gré-à-gré or mandataire). See Appendix E for more details on the French home care sector.
} 
where $Y$ denotes the composite good, with price set to 1 . The APA program creates a kink in the budget constraint of the beneficiary (Figure 1).

Figure 1: Budget constraint for home care under APA program

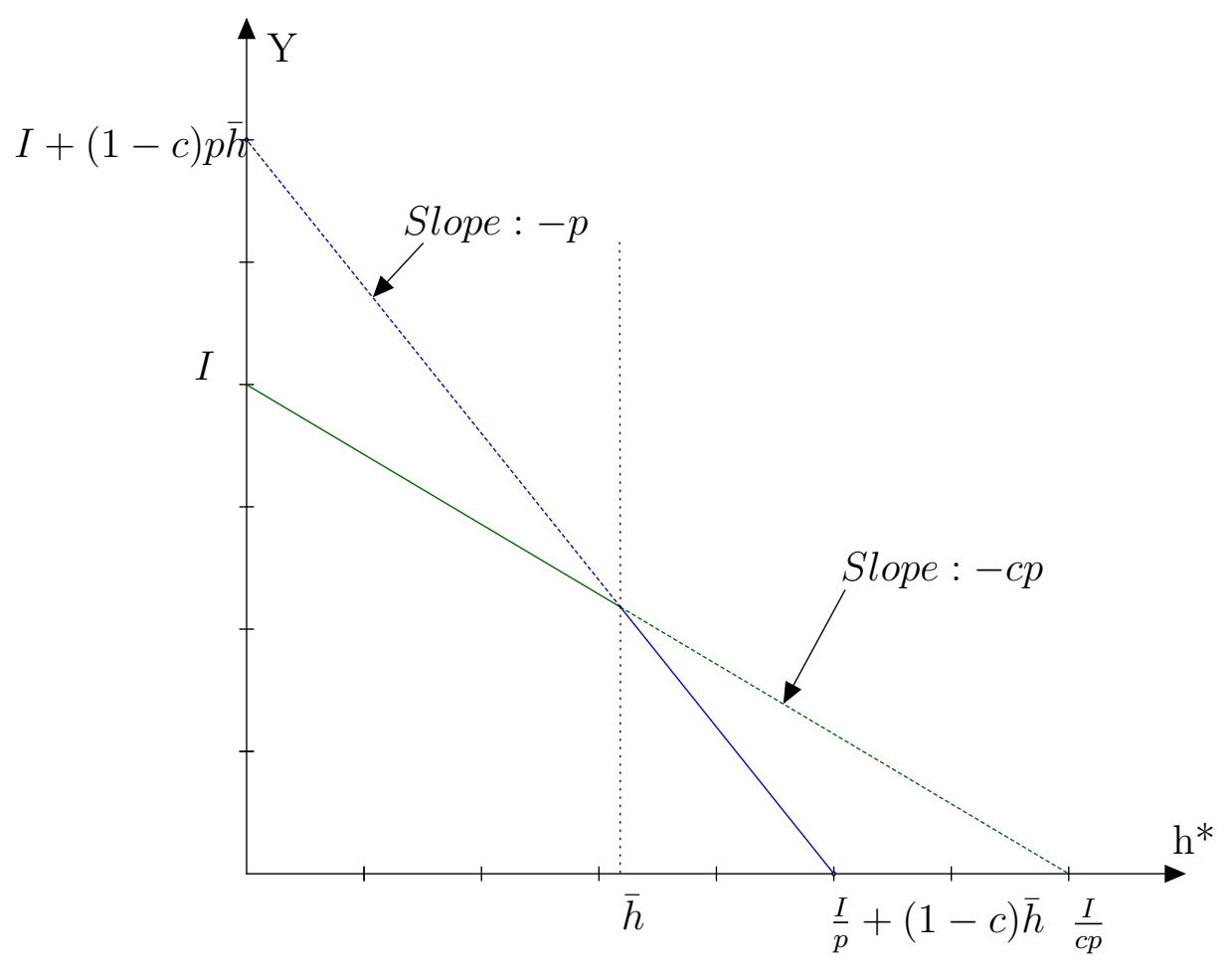

As shown by the previous system, when deciding upon an increase in home care consumption beyond $\bar{h}_{i}$, the individual should take into account not only her monetary disposable income $I_{i}$ but also the subsidies received on the first $\bar{h}_{i}$ hours of care she has consumed. Denoting $\tilde{I}_{i}=I_{i}+\left(1-c_{i}\right) p_{i} \bar{h}_{i}$ the "virtual" income of individual $i$ (Moffitt, 1986, 1990), we rewrite the demand function specified in Equation (1) as follows:

$$
\begin{cases}h_{i}^{*}=g\left(c_{i} p_{i}, I_{i} ; X_{i}\right)+\nu_{i} & \text { if } h_{i}^{*}<\bar{h}_{i} \\ g\left(p_{i}, \tilde{I}_{i} ; X_{i}\right)+\nu_{i} \leq \bar{h}_{i} \leq g\left(c_{i} p_{i}, I_{i} ; X_{i}\right)+\nu_{i} & \text { if } h_{i}^{*}=\bar{h}_{i} \\ h_{i}^{*}=g\left(p_{i}, \tilde{I}_{i} ; X_{i}\right)+\nu_{i} & \text { if } h_{i}^{*}>\bar{h}_{i}\end{cases}
$$

The objective of the paper is to obtain an empirical estimate of the following quantity, which is the point price elasticity:

$$
\frac{\mathrm{d} g(C P, \hat{I} ; X)}{\mathrm{d} C P} \frac{C P}{g(C P, \hat{I} ; X)}
$$




\section{DATA}

\subsection{Administrative data from a Departmental Council}

In France, there is no national survey or administrative data set that provides precise information on both the OOP payments and the formal home care use of the disabled elderly. We collected data from one Departmental Council that uses the most frequent APA subsidy computation rule. We selected a department with demographic characteristics close to the national averages, although its population has higher than average incomes (Appendix A.1).

Data were collected for every month in 2012-2014. Since within year variation in provider prices is negligible, we only use data for the month of October, ${ }^{7}$ when home care consumption is less likely to be affected by temporary shocks (like holidays and visits from children).

\subsection{Sample selection}

To ensure clean identification, we focus on APA beneficiaries served by an authorized home care provider for which the provider price is observed: we exclude $23 \%$ of beneficiaries of the initial sample as they receive care from other providers. We also exclude beneficiaries with missing information on subsidized consumption around the month of interest, so as to limit the risk that unobserved shocks (temporary absences or hospitalizations) could bias the estimates.

In addition, we exclude beneficiaries whose co-payment rate is zero: their OOP price on subsidized hours is zero. We also exclude beneficiaries whose copayment is equal to $90 \%$ : the relationship between their disposable income and their co-payment rate is not linear and this makes identification more complex. We end up with 8,190 individuals, or about 2,700 per year, representing $51 \%$ of the initial sample. ${ }^{8}$

\footnotetext{
${ }^{7}$ Averaging consumption and OOP prices on an annual basis would hamper identification by blurring the true empirical relationship between price and consumption.

${ }^{8}$ Appendix A.2 provides more details.
} 


\subsection{Descriptive statistics}

Columns [3] and [4] of Table I describe our estimation sample for October 2014. ${ }^{9}$ The typical individual is a woman, in her mid-80s and living alone. Six APA beneficiaries out of ten do not consume their full care plan volume; price sensitivity is one possible candidate to explain part of this high figure.

Columns [1] and [2] present the same statistics for two larger populations we selected our final sample from (all APA beneficiaries / all beneficiaries with an authorized provider). The last two columns indicate whether our sample and the larger samples differ in statistical terms. Differences are significant in terms of income and disability level, translating into differences in co-payment rate and care plan volume and value. ${ }^{10}$

\section{EMPIRICAL STRATEGY}

\subsection{A censored measure of home care consumption}

APA files register the individual number of home care hours that are charged by the provider to the Departmental Council or, equivalently, the subsidized hours of home care. However, we do not observe the total volume of home care consumed by each APA beneficiary. For the beneficiaries whose recorded consumption equals their care plan volume (40\% of our sample), our measure of home care consumption is then right-censored. ${ }^{11}$

Denote $h_{i}$ the number of home care hours billed to the Departmental Council for beneficiary $i$. We observe:

$$
\left\{\begin{array}{lll}
h_{i}=g\left(c_{i} p_{i}, I_{i} ; X_{i}\right)+\nu_{i} & \text { if } & g\left(c_{i} p_{i}, I_{i} ; X_{i}\right)+\nu_{i}<\bar{h}_{i} \\
h_{i}=\bar{h}_{i} & \text { if } \quad g\left(c_{i} p_{i}, I_{i} ; X_{i}\right)+\nu_{i} \geq \bar{h}_{i}
\end{array}\right.
$$

Hence, the parameters of the demand function $g($.$) can only be identified$ from information relating to the first segment of the budget constraint. For individuals with the maximum number of billed hours $\bar{h}_{i}$, the only information

\footnotetext{
${ }^{9}$ We present the data of October 2014 to draw a better picture of the population of interest. Appendix ?? replicates these statistics for the pooled sample.

${ }^{10}$ Implications for the external validity of the analysis will be discussed in Section 5 .

${ }^{11}$ No public source, at either the departmental or the national level, provides information on home care consumption beyond the care plan volume. However, data collected on a large provider operating in a French department show that $17 \%$ of its customers receiving APA consume strictly more than their care plan volume, with a median "over-consumption" of 1.5 hour per month (Fontaine and Gramain, forthcoming).
} 
Table I: Descriptive statistics for estimation sample and all program beneficiaries (October 2014)

\begin{tabular}{|c|c|c|c|c|c|c|}
\hline & $\begin{array}{l}\text { All benefi- } \\
\text { ciaries }\end{array}$ & $\begin{array}{l}\text { Beneficiaries } \\
\text { with an } \\
\text { authorized } \\
\text { provider }\end{array}$ & \multicolumn{2}{|c|}{ Estimation sample } & \multicolumn{2}{|c|}{$\begin{array}{c}\text { Differences } \\
\text { between } \\
\text { samples }\end{array}$} \\
\hline Variable & $\begin{array}{c}\text { Mean } \\
{[1]}\end{array}$ & $\begin{array}{c}\text { Mean } \\
{[2]}\end{array}$ & $\begin{array}{c}\text { Mean } \\
{[3]}\end{array}$ & $\begin{array}{l}\text { Std-dev. } \\
{[4]}\end{array}$ & $\begin{array}{r}\mathrm{P}- \\
{[1]-[3]}\end{array}$ & $\begin{array}{l}\text { lue } \\
{[2]-[3]}\end{array}$ \\
\hline $\begin{array}{l}\text { Care plan volume }[\mathrm{a}] \\
\text { Care plan monetary value }[\mathrm{b}] \\
\text { Hours effectively subsidized }[\mathrm{c}] \\
\text { Amount of effective subsidies }[\mathrm{d}] \\
{[\mathrm{c}] \text { inferior to }[\mathrm{a}]} \\
\text { Ratio }[\mathrm{c}] /[\mathrm{a}] \\
\text { Ratio }[\mathrm{d}] /[\mathrm{b}]\end{array}$ & $\begin{array}{l}\text { n.a. } \\
\text { n.a. } \\
\text { n.a. } \\
\text { n.a. } \\
\text { n.a. } \\
\text { n.c. } \\
\text { n.c. }\end{array}$ & $\begin{array}{l}21.9 \\
€ 471.7 \\
\text { n.a. } \\
\text { n.a. } \\
\text { n.a. } \\
\text { n.c. } \\
\text { n.c. }\end{array}$ & $\begin{array}{c}20.5 \\
€ 455.5 \\
17.7 \\
€ 300.8 \\
59.8 \% \\
85.0 \% \\
65.1 \%\end{array}$ & $\begin{array}{c}10.7 \\
€ 238.3 \\
10.9 \\
€ 201.4 \\
- \\
20.7 \mathrm{pp} . \\
22.2 \mathrm{pp} .\end{array}$ & $\begin{array}{l}\text { n.c. } \\
\text { n.c. } \\
\text { n.c. } \\
\text { n.c. } \\
\text { n.c. } \\
\text { n.c. } \\
\text { n.c. }\end{array}$ & $\begin{array}{l}0.00 \\
0.00 \\
\text { n.c. } \\
\text { n.c. } \\
\text { n.c. } \\
\text { n.c. } \\
\text { n.c. }\end{array}$ \\
\hline $\begin{array}{l}\text { Individualized income } \\
\text { co-payment rate } \\
\text { Authorized provider price } \\
\text { Hourly OOP price } \\
\text { Total OOP payments } \\
\text { on subsidized hours }\end{array}$ & $\begin{array}{l}€ 1,324.5 \\
24.4 \% \\
\text { n.a. } \\
\text { n.a. } \\
\text { n.a. }\end{array}$ & $\begin{array}{l}€ 1,264.6 \\
22.3 \% \\
€ 22.2 \\
€ 4.9 \\
€ 84.5\end{array}$ & $\begin{array}{l}€ 1,315.8 \\
23.7 \% \\
€ 22.2 \\
€ 5.2 \\
€ 91.3\end{array}$ & $\begin{array}{l}€ 422.5 \\
17.3 \mathrm{pp} \\
€ 1.3 \\
€ 3.8 \\
€ 98.6\end{array}$ & $\begin{array}{l}0.00 \\
0.01 \\
\text { n.c. } \\
\text { n.c. } \\
\text { n.c. }\end{array}$ & $\begin{array}{l}0.00 \\
0.00 \\
0.04 \\
0.00 \\
0.00\end{array}$ \\
\hline $\begin{array}{l}\text { Age } \\
\text { Women }\end{array}$ & $\begin{array}{l}\text { n.a. } \\
76.7 \%\end{array}$ & $\begin{array}{c}84.1 \\
73.8 \%\end{array}$ & $\begin{array}{c}84.2 \\
74.0 \%\end{array}$ & $\begin{array}{l}7.4 \\
-\end{array}$ & $\begin{array}{l}\text { n.c. } \\
0.03\end{array}$ & $\begin{array}{l}0.29 \\
0.76\end{array}$ \\
\hline $\begin{array}{l}\text { Disability level } 1 \text { (most severe) } \\
\text { Disability level } 2 \\
\text { Disability level } 3 \\
\text { Disability level } 4 \text { (least severe) }\end{array}$ & $\begin{array}{l}1.5 \% \\
14.5 \% \\
21.2 \% \\
62.8 \% \\
100 \%\end{array}$ & $\begin{array}{l}1.3 \% \\
13.8 \% \\
21.0 \% \\
63.9 \% \\
100 \%\end{array}$ & $\begin{array}{l}1.2 \% \\
12.5 \% \\
19.6 \% \\
66.7 \% \\
100 \%\end{array}$ & $\begin{array}{l}- \\
- \\
-\end{array}$ & 0.00 & 0.00 \\
\hline $\begin{array}{l}\text { Living with a spouse } \\
\text { Living alone } \\
\text { Spouse in institution }\end{array}$ & $\begin{array}{l}32.1 \% \\
66.6 \% \\
1.3 \% \\
100 \% \\
\end{array}$ & $\begin{array}{c}31.0 \% \\
67.5 \% \\
1.6 \% \\
100 \%\end{array}$ & $\begin{array}{c}33.8 \% \\
65.6 \% \\
0.6 \% \\
100 \% \\
\end{array}$ & $\begin{array}{l}- \\
- \\
-\end{array}$ & 0.00 & 0.00 \\
\hline $\begin{array}{l}\text { Number of individuals } \\
\text { Number of households }\end{array}$ & $\begin{array}{l}5,486 \\
\text { n.a. }\end{array}$ & $\begin{array}{l}4,199 \\
\text { n.a. }\end{array}$ & & & - & - \\
\hline
\end{tabular}

SAMPLES: [1]: sample of all at-home APA beneficiaries of the department; [2]: sample of beneficiaries who receive care, but not necessarily exclusively, from an authorized provider; [3] and [4]: estimation sample.

Notes: "pp." stands for percentage points, "n.a." for "not available", "n.c." for "not computable" (available information is insufficient). Information on care plan volume, effective consumption and provider price is not available when the beneficiary receives care from a non-authorized provider. Care plan volume and effective home care consumption are expressed in hours per month; income, subsidies and total OOP payments are expressed in euros per month. Data from October 2014.

TESTs: The last two columns present the p-values from the tests of difference between the estimation sample and non-selected beneficiaries. The test performed is a Student (resp. Pearson $\chi^{2}$ ) test if variable is binary or continuous (resp. categorical). The tests compare the mean or distribution in the estimation sample with the reference sample ([1] or [2]) excluding the estimation sample.

we can use is that their demand is at least as high as this number. ${ }^{12}$

\footnotetext{
${ }^{12}$ Appendix $\mathrm{C}$ provides more details.
} 


\subsection{Econometric specification}

Since the distribution of (observed) home care consumption is slightly skewed, we assume a log-linear specification of $g($.$) , as follows:$

$$
\ln \left(h_{i t}^{*}\right)=\beta_{0}+\beta_{1} \cdot \ln \left(c_{i t} \cdot p_{i t}^{j}\right)+\beta_{2} \cdot \ln \left(I_{i t}\right)+X_{i t}^{\prime} \cdot \theta+\lambda_{t}+\epsilon_{i t}
$$

where $p_{i t}^{j}$ denotes the price charged by provider $j$ chosen by individual $i$ in year $t^{13}$ and $\lambda_{t}$ are year fixed effects. Both price and income are included in $\log$ so that $\beta_{1}$ represents the consumer price elasticity and $\beta_{2}$ captures the income elasticity of the demand for home care services. As $c($.$) is fully linear$ in income in the sample, ${ }^{14}$ Equation 3 can be rewritten as:

$$
\ln \left(h_{i t}^{*}\right)=\gamma_{0}+\beta_{1} \cdot \ln \left(p_{i t}^{j}\right)+\left(\beta_{1}+\beta_{2}\right) \cdot \ln \left(I_{i t}\right)+X_{i t}^{\prime} \cdot \theta+\lambda_{t}+\epsilon_{i t}
$$

Equation (4) makes it clear that the income variations identify the $\mathrm{em}$ pirical income effect within the APA framework. With APA, any marginal increase in the disposable income has two effects. First, it increases home care consumption, provided home care is a normal good (standard income effect). Then, it induces the reassessment of the co-payment rate, which may further affect home care consumption through an increased OOP price (price effect).

As System (2) corresponds to the typical observational scheme underlying censored regression model, $\beta_{1}$ and $\beta_{2}$ can be estimated by Maximum Likelihood after making a parametric assumption on $\epsilon$ (Tobit model). ${ }^{15}$ Our favoured specification though, is a more flexible version of Equation (4). In Equation (9), we take as dependent variable the log-share of the care plan volume consumed by the individual, $h_{i t}^{*} / \bar{h}_{i t}$ (call it "relative consumption") and include the care plan volume $\bar{h}_{i t}$ as a control. Equation (4) is nested in Equation (9) and $\tilde{\beta}_{1}$ can still be interpreted as a price elasticity. ${ }^{16}$

$$
\ln \left(h_{i t}^{*} / \bar{h}_{i t}\right)=\tilde{\gamma}_{0}+\tilde{\beta}_{1} \cdot \ln \left(p_{i t}^{j}\right)+\left(\tilde{\beta}_{1}+\tilde{\beta}_{2}\right) \cdot \ln \left(I_{i t}\right)+\tilde{\beta}_{3} \cdot \ln \left(\overline{h_{i t}}\right)+X_{i t}^{\prime} \cdot \tilde{\theta}+\tilde{\lambda}_{t}+\tilde{\epsilon}_{i t}
$$

This specification comes with several advantages. First, it includes $\bar{h}_{i t}$ as a control, which might be a proxy of the unobserved determinants of consump-

\footnotetext{
${ }^{13}$ All beneficiaries with the same provider are charged the same provider price, before APA co-payment rate applies.

${ }^{14}$ The relationship between $c_{i t}$ and $I_{i t}$ depends on the year the co-payment rate was set. We control for this source of inter- and intra-individual variation in our estimations. Appendix B.1 provides more details.

${ }^{15}$ Appendix $\mathrm{C}$ derives the Maximum Likelihood function.

${ }^{16}$ Appendix B.1 provides more details.
} 
tion. ${ }^{17}$ Technically, relative home care consumption has a better-behaved distribution than absolute consumption, making parametric estimates more likely to be consistent. ${ }^{18}$ Its censoring point is unique (equal to 0 ), which eases the implementation of the estimation.

Our baseline estimates are obtained fitting a population-average ${ }^{19}$ censored regression estimation of Equation (9) assuming that:

$$
\tilde{\epsilon} \quad \mid \quad p, I, \bar{h}, X, \tilde{\lambda} \sim \mathcal{N}\left(0, \tilde{\sigma}^{2}\right)
$$

\subsection{Identification using cross-sectional variations in prices}

As suggested by Equations (4) and (9), the consumer price elasticity of demand is identified by the cross-sectional variation in provider prices. In the department, there are 28 authorized providers. Each provider price is reassessed every year. In the panel, provider prices range from $€ 19.35$ to $€ 23.50$, with an average of $€ 21.8$ and a standard-deviation of $€ 1$.3. As yearly variation in prices was small between 2012 and 2014, most of the price variation is cross-sectional. ${ }^{20}$

To get unbiased estimates, the provider price charged to individual $i$ must be uncorrelated with the unobserved factors affecting her home care consumption, $\epsilon_{i}$. Supply-demand simultaneity may violate this condition (Zhen et al., 2014), but it should be negligible in our context. Indeed, although each provider is priced by the Departmental Council on the basis of its average production cost of two years earlier, the pricing process largely depends on administrative and political considerations (Gramain and Xing, 2012).

The risk of omitted variable biases is more difficult to dismiss. Beneficiaries may non-randomly select their provider (price) on the basis of some unobservable individual characteristics such as quality expectations, unobserved health condition or informal care provision (Billaud et al., 2012). Some sources of price variations can be documented and are unlikely to be correlated with unobserved determinants of home care consumption (Appendix F), but it is insufficient to rule out any price endogeneity induced by non-random provider

\footnotetext{
${ }^{17}$ The care plan volume is supposedly based only on the specific activity restrictions of the beneficiary; but qualitative studies have shown that the evaluation team is likely to take into account additional characteristics of the individual, such as the informal care she receives (Billaud et al., 2012).

${ }^{18}$ See Figures B.1 and B.2 in Appendix B.2.

${ }^{19}$ We use the unbalanced sample: selecting individuals staying in the APA programme for three years would raise additional selection issues.

${ }^{20}$ On average, provider prices increased by $1.9 \%$ between October 2012 and 2013 and by $1.3 \%$ between 2013 and 2014.
} 
choice. To address this potential bias, we exploit the unequal spatial coverage by authorized providers in the department.

\subsection{An instrumental variable strategy}

We propose to instrument the provider price by the number of municipalities in which the provider serves APA beneficiaries and estimate an IV-Tobit. To be valid, our instrument must first correlate with the price, conditional on the control variables. Second, it must be uncorrelated with the unobserved determinants of professional home care consumption.

From a practical standpoint, serving more municipalities translates into higher transportation and coordination costs for a provider. Exploiting the service files of a large French home care provider, an ongoing study suggests that the monetary costs associated to the travels of caregivers could represent from 4 to $20 \%$ of the price charged by a provider. This share is found to vary with the organization of caregivers' rounds. For authorized providers, such costs are partially incorporated in the price set by the Departmental Council (Gramain and Xing, 2012). Several public and research reports on the French home care sector have insisted on the heterogeneity in transportation costs borne by providers and the differences in prices it induces (Aube-Martin et al., 2010; Vanlerenberghe and Watrin, 2014; Branchu et al., 2015; Garabige et al., 2015).

In our data, as is evidenced by Figure G.4, the price charged by a given provider and the number of municipalities in which it operates are positively correlated. The IV-Tobit first stage (Table II) shows that a one standarddeviation increase in the number of municipalities served by the provider is associated with a $4.9 \%$ increase in its price. The F-statistic associated with this estimate exceeds 143 - a figure far higher than the conventional threshold used to assess the risk that the instrument is weak (Staiger and Stock, 1997).

A potential threat to the exclusion restriction is that the instrument may correlate with individual consumption through another channel than the price charged by the provider. In particular, it would be the case if the number of hours provided by a service systematically increases its provision costs due to decreasing returns to scale. Apart from transportation and coordination costs though, the care provision process may be assumed to exhibit roughly constant returns to scale, as most of the provision costs is made of caregivers' wages. The strong association between the price charged by a provider and its geographical area of operation is thus unlikely to be driven by the volume 
of care it delivers.

Figure 2: Correlation between provider price and number of municipalities served by the provider

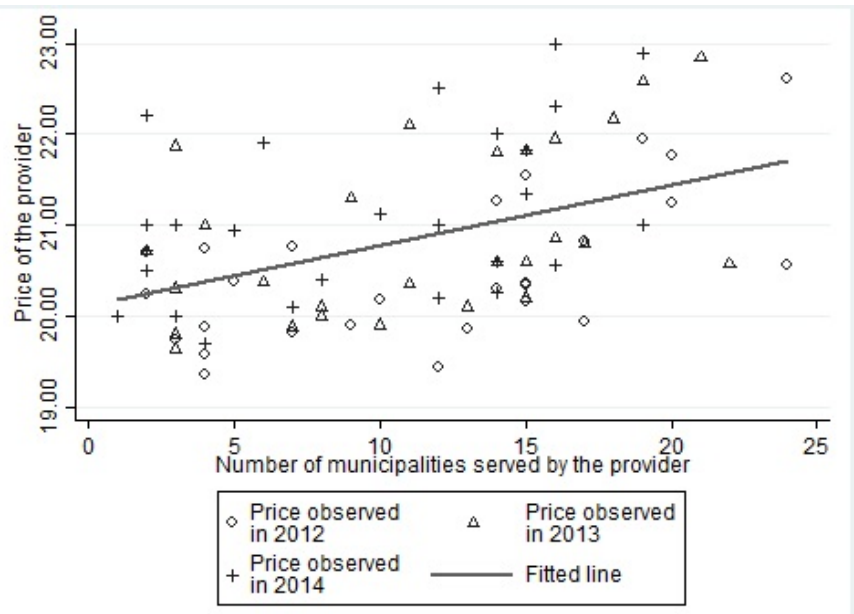

Notes: The number of municipalities served by each provider is constructed using information on all APA beneficiaries receiving home care from an authorized provider in October 2012, 2013 and 2014 (and not just the beneficiaries retained in the estimation sample). The line is fitted using all three years of observation. To make the graphical representation more readable, we excluded the largest provider. With 199 municipalities served in October 2014 , it charged the highest price over the 3 years of observation ( $€ 23.5$ in 2014). The positive correlation displayed by the graph is preserved when we include the largest provider.

\section{RESULTS AND DISCUSSION}

\subsection{Main results}

Table II presents our main results, obtained on the panel data. ${ }^{21}$ Column (1) presents Tobit estimates of Equation (9). Column (2) presents the estimates we obtain when the price is instrumented by the number of municipalities served by the provider. ${ }^{22}$ We cluster the standard errors at the provider level since our "treatment" variable, $p_{i t}^{j}$, essentially varies at the provider level (Moulton, 1990; Cameron and Miller, 2015).

When the provider price is considered as exogenous, the consumer price elasticity estimate is about -0.45 . When using our instrument, the coeffi-

\footnotetext{
${ }^{21}$ The coefficients displayed give the predicted impact of a marginal (or 0/1) change in a given explanatory variable on the total, uncensored relative home care consumption.

${ }^{22}$ We use the parametric version of Stata command ivtobit. We thus assume the error terms of the first-stage and second-stage equations are jointly normally distributed.
} 
Table II: Censored regression estimates of demand for home care hours

\begin{tabular}{|c|c|c|}
\hline & $\begin{array}{c}\text { Tobit }- \\
(1)\end{array}$ & $\begin{array}{l}I V-\text { Tobit }- \\
(2)\end{array}$ \\
\hline Panel A: Second stage & \multicolumn{2}{|c|}{ Dependent variable: relative consumption $h^{*} / \bar{h}(\log )$} \\
\hline Price $(\log )$ & $\begin{array}{c}-0.450^{* *} \\
(0.181)\end{array}$ & $\begin{array}{c}-0.387^{* *} \\
(0.192)\end{array}$ \\
\hline Disposable income (log) & $\begin{array}{l}-0.010 \\
(0.008)\end{array}$ & $\begin{array}{l}-0.010 \\
(0.008)\end{array}$ \\
\hline Care plan volume (log) & $\begin{array}{l}0.040^{*} \\
(0.023)\end{array}$ & $\begin{array}{l}0.040^{*} \\
(0.023)\end{array}$ \\
\hline Woman & $\begin{array}{l}0.029^{* *} \\
(0.014)\end{array}$ & $\begin{array}{l}0.030^{* *} \\
(0.014)\end{array}$ \\
\hline Age: $60-69$ & $\begin{array}{c}-0.124^{* * *} \\
(0.047)\end{array}$ & $\begin{array}{c}-0.123^{* * *} \\
(0.047)\end{array}$ \\
\hline Age: $70-79$ & $\begin{array}{c}-0.042^{* *} \\
(0.017)\end{array}$ & $\begin{array}{c}-0.042^{* *} \\
(0.017)\end{array}$ \\
\hline Age: $80-89$ & Ref. & Ref. \\
\hline Age: 90 or older & $\begin{array}{c}0.051^{* * *} \\
(0.015)\end{array}$ & $\begin{array}{c}0.052^{* * *} \\
(0.015)\end{array}$ \\
\hline Disability group: 1 (most severe) & $\begin{array}{c}0.154^{* * *} \\
(0.057)\end{array}$ & $\begin{array}{c}0.153^{* * *} \\
(0.057)\end{array}$ \\
\hline Disability group: 2 & $\begin{array}{c}0.027 \\
(0.022)\end{array}$ & $\begin{array}{c}0.027 \\
(0.022)\end{array}$ \\
\hline Disability group: 3 & Ref. & Ref. \\
\hline Disability group: 4 (least severe) & $\begin{array}{c}0.008 \\
(0.012)\end{array}$ & $\begin{array}{c}0.009 \\
(0.012)\end{array}$ \\
\hline Living with no spouse & $\begin{array}{c}0.107^{* * *} \\
(0.013)\end{array}$ & $\begin{array}{c}0.107^{* * *} \\
(0.013)\end{array}$ \\
\hline Spouse receives APA & $\begin{array}{c}0.036 \\
(0.034)\end{array}$ & $\begin{array}{c}0.037 \\
(0.034)\end{array}$ \\
\hline Spouse in institution & $\begin{array}{l}0.170^{*} \\
(0.095)\end{array}$ & $\begin{array}{l}0.170^{*} \\
(0.094)\end{array}$ \\
\hline Living with non-APA spouse & Ref. & Ref. \\
\hline Constant & $\begin{array}{l}1.225^{* *} \\
(0.556)\end{array}$ & $\begin{array}{l}1.032^{*} \\
(0.592)\end{array}$ \\
\hline
\end{tabular}

Panel B: First stage

Dependent variable: provider price $p(\log )$

Number of municipalities (std.)

$0.049^{* * *}$

(0.004)

F statistic

143.98

Observations

Censored observations

Number of clusters

$A I C$

$B I C$

11454

11644
8190

$39.6 \%$

28

$-22049$

$-21860$

NOTES: Standard errors in parentheses, clustered at the provider level; ${ }^{*} p<0.10$, ${ }^{* *} p<0.05,{ }^{* * *} p<0.01$. Pooled data from October 2012, 2013 and 2014. Estimation of a Tobit or IV-Tobit model by Maximum Likelihood. In the first stage (Panel B), the $\log$-provider price is regressed on the standardized number of municipalities served by the provider. All specifications include year fixed effects, dummies for the year in which the co-payment rate was computed as well as dunmmies for the year the latest plan was decided upon (in the first and second stages for the IV-Tobit estimation). 
cient is slightly lower in absolute value. The difference between the two is not statistically significant, suggesting that the potential bias due to non-random provider selection may be limited. ${ }^{23}$ Overall, price elasticity estimates are negative, statistically significant, confirming that the disabled elderly are sensitive to the price of professional home care. Our favoured estimation (Column (2)), which instruments the price, gives a point estimate of -0.387 , or about -0.4 .

The income effect in the APA framework appears negative, but negligible and statistically not different from zero. Richer APA beneficiaries do not tend to consume more formal care, all other things being equal. With $\hat{\tilde{\beta}}_{1}+\hat{\tilde{\beta}}_{2}$ close to zero, our estimations suggest that the increase in the co-payment rate, induced by an increase in income, compensates for the standard income effect. We also derive an estimate of the standard income elasticity $\tilde{\beta}_{2}$. Both the Tobit and the IV-Tobit give a value of about 0.4 , statistically different from zero. Although this income effect is imprecisely estimated, ${ }^{24}$ we are able to conclude that home care is a necessity good for the disabled elderly.

Individuals with a higher care plan volume tend to consume a larger share of their care plan. For a given disability level, a higher care plan volume could be explained by a lower provision of informal care. Alternatively, a higher care plan may also have a stronger prescriptive effect.

As expected, the highly-disabled individuals consume relatively more than the beneficiaries with mild to moderate disability, all other factors being equal. Even when controlling for the disability level, age retains a significant effect on the consumption on home care services. Being a woman increases the consumption of professional home care relative to the care plan volume, by a small but statistically significant amount. Living alone (spouse in institution or no spouse) increases the amount of professional assistance received, consistently with previous works showing the importance of the co-residing spouse in providing informal care substituting partly for formal home care services.

\subsection{Further results and robustness checks}

We replicate the estimations on each year separately (Appendix G.1); price elasticity estimates are found to range from -0.54 to -0.13 . Precision is low

\footnotetext{
${ }^{23}$ We implement a cluster Bootstrap Hausman test. We cannot reject that the provider price is exogenous $(p=0.88)$.

${ }^{24} \hat{\tilde{\beta}}_{2}$ corresponds to the difference between the empirical income elasticity with APA and the price elasticity estimates; the associated standard error is high (around 0.19), due to the relatively large standard error of the price elasticity estimate.
} 
but we can reject that the price elasticity is zero (except for 2014) or unity. ${ }^{25}$ We check our results are robust to the fact that inference relies on a small number of clusters by implementing a cluster percentile-t bootstrap (Appendix G.2). Statistical significance of the price elasticity is preserved at the $5 \%$ level on the pooled sample.

To investigate the potential heterogeneity in price sensitivity, we estimate the model interacting the price with the disability level or the income level (Table III).

Table III: Price elasticity of home care by severity of disability and income

\begin{tabular}{|c|c|c|c|}
\hline Dependent variable & relative & sumptiol & $\imath^{*} / h(\log )$ \\
\hline & (1) & $(2)$ & $(3)$ \\
\hline Price (log) & $\begin{array}{c}-0.450^{* *} \\
(0.181)\end{array}$ & $\begin{array}{c}-0.323 \\
(0.236)\end{array}$ & $\begin{array}{r}-0.446^{* *} \\
(0.178)\end{array}$ \\
\hline Price $(\log ) \times$ disability group 4 (least severe) & & $\begin{array}{l}-0.190 \\
(0.270)\end{array}$ & \\
\hline Price $(\log ) \times$ income above median & & & $\begin{array}{c}-0.019^{* * *} \\
(0.006)\end{array}$ \\
\hline Disposable income (log) & $\begin{array}{l}-0.010 \\
(0.008) \\
\end{array}$ & $\begin{array}{l}-0.010 \\
(0.008)\end{array}$ & $\begin{array}{c}0.011 \\
(0.010)\end{array}$ \\
\hline Observations & 8190 & 8190 & 8190 \\
\hline Censored observations & $39.6 \%$ & $39.6 \%$ & $39.6 \%$ \\
\hline Number of clusters & 28 & 28 & 28 \\
\hline$A I C$ & 11454 & 11453 & 11439 \\
\hline$B I C$ & 11643 & 11642 & 11629 \\
\hline $\begin{array}{l}\text { NOTES: Standard errors in parentheses, clustere } \\
{ }^{* *} p<0.05,{ }^{* *} p<0.01 \text {. Pooled data from Oc } \\
\text { tion of Tobit model by Maximum Likelihood. } \\
\text { the care plan volume, socio-demographic charac } \\
\text { for the year in which the co-payment rate was c } \\
\text { year the latest plan was decided upon. }\end{array}$ & $\begin{array}{l}\text { the pr } \\
\text { ser } 2012 \\
\text { specific } \\
\text { istics, y } \\
\text { puted a }\end{array}$ & $\begin{array}{l}\text { er leve } \\
3 \text { and } \\
\text { s incl } \\
\text { xed ef } \\
\text { las d }\end{array}$ & $\begin{array}{l}p<0.10 \\
\text { 4. Estima- } \\
\text { as controls } \\
\text {, dummies } \\
\text { aies for the }\end{array}$ \\
\hline
\end{tabular}

A credible IV strategy would require to find an additional instrument for each interaction term. As Table II suggests that the bias due to potential price endogeneity is limited, we fit a simple Tobit model when adding the interaction terms. We expected more severely disabled individuals to be less price sensitive, but we are not able to detect such an effect. Price sensitivity is higher for individuals whose income is above the sample median income. This result echoes Duarte (2012), who finds that higher income individuals are more price elastic in their medical care consumption. Richer individuals may

\footnotetext{
${ }^{25}$ Precision in 2014 is lower, as a provider closed down.
} 
be more able to understand the health care system and cost-sharing schedules due to a higher financial literacy.

As a robustness check, we implement an alternative identification strategy (Appendix G.3). We estimate our equation of interest (without instrumenting the price) on the sub-sample of APA beneficiaries who live in a municipality where a single authorized provider is found to operate. In a context in which price selection is arguably limited, we find a price elasticity estimate around -0.5- not statistically different from our main result.

\subsection{Discussion}

Our results confirm that the consumption of home care of the disabled elderly is sensitive to the price they pay. Decisions relating to formal home care consumption are influenced by a trade-off between the OOP price of an extra hour and its marginal value. Such a pecuniary trade-off has been documented at the extensive margin, as the take-up of APA benefits is affected by the average subsidy rate in the department (Arrighi et al., 2015). Innovatively, we find evidence that the price elasticity of the demand for home care is seemingly lower than unity at the intensive margin: the adjustment of consumption is proportionally lower than a given change in price. This implies a positive price elasticity of OOP expenditures: a decrease in the OOP price should lead to a decrease in total OOP payments.

The price sensitivity we obtain is of an order of magnitude similar to the estimates found for health care demand. Although the magnitude of the -0.2 estimate derived from the Rand Health Insurance Experiment (Manning et al., 1987; Keeler and Rolph, 1988) is subject to discussion (Aron-Dine et al., 2013), a large literature has confirmed that medical spending is price-elastic, with price sensitivity varying with the type of care (Duarte, 2012; Fukushima et al., 2016). Our paper provides interesting evidence that, at the intensive margin, home care consumption is closer to acute care than to elective care in terms of price sensitivity.

Our OOP price measure does not take into account possible tax reductions on home care services, unobserved in the APA records. Without sufficient information to simulate them, we implicitly assume APA beneficiaries to be sensitive to the "spot" price (Geoffard, 2000). We also assume that APA recipients react in the same way to variations in the co-payment rate and in the provider price. If salience differs (Chetty et al., 2009), implications for the design of the co-payment schedule are less straightforward. 
In our administrative data, information on family characteristics is poor. Receiving more informal care has been found to decrease formal care use, both at the extensive and intensive margins (Van Houtven and Norton, 2004; Bonsang, 2009). Omitting informal care provision could bias the estimates of our entire set of coefficients. This is all the more of a concern as the share of (self-declared) APA beneficiaries who declare receiving some informal help is higher in the department than in the rest of France. ${ }^{26}$ As a robustness check, we include as a control whether the individual receives formal home care during the weekend and public holidays (Appendix G.4). We hypothesize that individuals not receiving professional home care over the weekend are more likely to receive assistance from their relatives. Receiving formal care during the weekend is associated with more hours consumed during working days; reassuringly though, it does not significantly affect the price elasticity estimate.

Finally, external validity of our results should be qualified. Without data covering the entire population eligible to APA, the potential bias induced by the differential take-up of APA subsidies (Chauveaud and Warin, 2005) cannot be dealt with. Our sample is not nationally representative and we focus on APA recipients who consume home care from authorized services. As the department is slightly richer than France as a whole, and price sensitivity being greater for richer beneficiaries, our estimates may be an upper bound (in absolute value). Yet the department is reasonably close to "average France" in terms of other socio-demographic characteristics and most APA beneficiaries in France receive care from authorized providers (Hege et al., 2014). Finally, our results are in line with the two available estimates (Bourreau-Dubois et al., 2014; Hege, 2016), which rely on different estimation strategies and data.

\section{CONCLUSION}

This paper estimates the consumer price elasticity of the demand for professional home care services of the disabled elderly benefiting from the French APA program. Our results suggest this parameter is about -0.4 , with point estimates statistically different from zero and unity in absolute value.

Our findings pave the way for several policy implications. With income having no effect in the APA scheme, we can interpret our price elasticity estimate as a sufficient statistics for the substitution effect in home care subsidy

\footnotetext{
${ }^{26}$ Over four-fifths in the department, against 75\% in metropolitan France (Insee-Drees, 2014).
} 
schemes. As the disabled elderly are sensitive to the price of care, the copayment rates in home care subsidy programs entail allocative and dynamic efficiency issues. Given the low value of the price elasticity, the generosity of home care subsidies also has substantial redistributive effects from taxpayers to the disabled elderly.

While remaining cautious regarding the external validity of the results, our estimates can be used to discuss the effects of potential reforms of home care subsidies. The decrease of co-payment rates enacted by the 2016 APA reform, higher for low-income recipients, should reduce overall OOP expenses on professional home care of current APA recipients, while having a limited volume effect. 


\section{References}

Aron-Dine A., Einav L., Finkelstein A. 2013. The RAND Health Insurance Experiment, three decades later. Journal of Economic Perspectives 27(1): 197-222. 16

Arrighi Y., Davin B., Trannoy A., Ventelou B. 2015. The non-take up of long-term care benefit in France: A pecuniary motive?. Health Policy 119(10): 1338-1348. 16

Aube-Martin P., Bruant-Bisson A., De Reboul J.-B. 2010. Mission relative aux questions de tarification et de solvabilisation des services daide à domicile en direction des publics fragiles. Rapport RM2010-138P/ IGF 2010-M052-02. Inspection générale des affaires sociales, Inspection générale des finances. 11

Bakx P., Chernichovsky D., Paolucci F., Schokkaert E., Trottmann M., Wasem J., Schut F. 2015. Demand-side strategies to deal with moral hazard in public insurance for long-term care. Journal of Health Services Research \& Policy 20(3): 170-176. 1

Barnay T., Juin S. 2016. Does home care for dependent elderly people improve their mental health?. Journal of Health Economics 45: 149-160. 1

Billaud S., Bourreau-Dubois C., Gramain A., Lim H., Weber F., Xing J. 2012. La prise en charge de la dépendance des personnes âgées: les dimensions territoriales de l'action publique. Rapport final réalisé pour la MiRe/Drees. 10, 25, 39

Blanpain N., Buisson G. 2016. Projections de population à lhorizon 2070 : deux fois plus de personnes de 75 ans ou plus quen 2013. Insee Première 1619. Insee. 1

Bonsang E. 2009. Does informal care from children to their elderly parents substitute for formal care in Europe?. Journal of Health Economics 28(1): 143-154. 17

Bourreau-Dubois C., Gramain A., Lim H., Xing J. 2014. Impact du reste à charge sur le volume d'heures d'aide à domicile utilisé par les bénéficiaires de l'APA. CES Working Paper 2014.24. Centre d'Economie de la Sorbonne. 2, 17

Bourreau-Dubois C., Gramain A., Roquebert Q. 2015. Les disparités départementales dans la mise en oeuvre de IAPA à domicile, reflets des choix de politiques locales ?. Notes MODAPA 3.4

Branchu C., Jaouen V., Naves P. 2015. Evaluation des expérimentations relatives à la tarification des services daide et daccompagnement à domicile (SAAD). Rapport 2014-130R. Inspection générale des affaires sociales. 11

Cameron A. C., Gelbach J. B., Miller D. L. 2008. Bootstrap-based improvements for inference with clustered errors. The Review of Economics and Statistics 90(3): 414-427. 51

Cameron A. C., Miller D. L. 2015. A practitioner's guide to cluster-robust inference. Journal of Human Resources 50(2): 317-372. 12, 51, 52, 53 
Chauveaud C., Warin P. 2005. Des personnes âgées hors leurs droits. Non-recours subi ou volontaire. Rencontres avec des assistantes sociales. Etude 11. Odenore. Grenoble. 17

Chetty R., Looney A., Kroft K. 2009. Salience and taxation: Theory and evidence. American Economic Review 99(4): 1145-1177. 16

Colombo F., Llena-Nozal A., Mercier J., Tjadens F. 2011. Help wanted? Providing and paying for long-term care. OECD Health Policy Studies. OECD Publishing edn. OECD. Paris. 1

Coughlin T. A., McBride T. D., Perozek M., Liu K. 1992. Home care for the disabled elderly: predictors and expected costs. Health Services Research 27(4): 453-479. 2

Cutler D. M., Zeckhauser R. J. 2000. The anatomy of health insurance. in 'Handbook of Health Economics'. Elsevier Science edn. Vol. 1. A.J. Culyer and J.P. Newhouse. pp. 563643. 1

Debout C. 2010. La durée de perception de l'APA : 4 ans en moyenne. Etudes et résultats 724. Drees. 28

Deloffre A. 2009. Les retraites en 2007. Document de travail, Série Etudes et Recherches 86. Drees. 30

Drees 2013. Enquête annuelle Aide sociale auprès des conseils départementaux 2013. URL: $\quad h t t p: / / d r e e s . s o c i a l-s a n t e . g o u v . f r / e t u d e s-e t-s t a t i s t i q u e s / o p e n-d a t a / h a n d i c a p-$ et-dependance/le-handicap-et-la-dependance/article/donnees-concernant-l-allocationpersonnalisee-d-autonomie-apa 2, 24, 25

Drees 2014. Enquête annuelle Aide sociale auprès des conseils départementaux 2014.

URL: $\quad h t t p: / / d r e e s . s o c i a l-s a n t e . g o u v . f r / e t u d e s-e t-s t a t i s t i q u e s / o p e n-d a t a / h a n d i c a p-$ et-dependance/le-handicap-et-la-dependance/article/donnees-concernant-l-allocationpersonnalisee-d-autonomie-apa 2

Duarte F. 2012. Price elasticity of expenditure across health care services. Journal of Health Economics 31(6): 824-841. 15, 16

Ettner S. L. 1994. The effect of the Medicaid home care benefit on long-term care choices of the elderly. Economic Inquiry 32(1): 103-127. 1, 2

Fizzala A. 2016. Dépendance des personnes âgées : qui paie quoi ? L'apport du modèle Autonomix. Les dossiers de la Drees 1. Drees. 1

Fontaine R. 2012. The effect of public subsidies for formal care on the care provision for disabled elderly people in France. Économie publique/Public Economics (28-29): 271-304. 2

Fontaine R., Gramain A. forthcoming. Plan d'aide notifié et consommation effective d'aide à domicile dans le cadre de l'APA : une comparaison à partir des données de facturation d'un SAAD. Notes MODAPA 5. 7 
Fukushima K., Mizuoka S., Yamamoto S., Iizuka T. 2016. Patient cost sharing and medical expenditures for the elderly. Journal of Health Economics 45: 115-130. 16

Garabige A., Gomel B., Trabut L. 2015. Dynamiques de transformation des modèles économiques des structures de léconomie sociale et solidaire dans les services à domicile. Analyse de cas. Rapport 90. Centre d'Etude de l'Emploi. 11

Geoffard P.-Y. 2000. Dépenses de santé : l'hypothèse d'aléa moral. Economie et prévision 142(1): 122-135. 16

Gramain A., Xing J. 2012. Tarification publique et normalisation des processus de production dans le secteur de l'aide à domicile pour les personnes âgées. Revue française des affaires sociales (2012/2-3): 218-243. 10, 11, 42

Guo J., Konetzka R. T., Manning W. G. 2015. The causal effects of home care use on institutional long-term care utilization and expenditures. Health Economics 24(S1): 417. 1

Hege R. 2016. La demande d'aide à domicile est-elle sensible au reste-à-charge : une analyse multi-niveaux sur données françaises. CES Working Paper 2016.22. Centre d'économie de la Sorbonne. 2, 17

Hege R., Roquebert Q., Tenand M., Gramain A. 2014. La tarification des services d'aide à domicile : un outil au service des politiques départementales ?. Notes MODAPA 2. 17, 40

Imbens G. W., Kolesár M. 2015. Robust standard errors in small samples: Some practical advice. The Review of Economics and Statistics 98(4): 701-712. 51

Insee 2014. Estimations de population au $1^{\text {er }}$ janvier 2014, par département, sexe et âge quiquennal. Résultats provisoires arrêtés fin 2015.

URL: https://www.insee.fr/fr/statistiques/1893198 24, 25

Insee, DGFiP, Cnaf, Cnav, Ccmsa 2013. Fichier localisé social et fiscal (FiLoSoFi) 2013.

URL: https://www.insee.fr/fr/metadonnees/source/s1172 24, 25

Insee-Drees 2014. Enquête Vie quotidienne et santé.

URL: https://www.insee.fr/fr/metadonnees/source/s1279 17, 24, 25

Keeler E. B., Rolph J. E. 1988. The demand for episodes of treatment in the health insurance experiment. Journal of Health Economics 7(4): 337-367. 16

Laferrère A. 2008. Les seniors de moins en moins mobiles, les jeunes toujours plus mobiles : lévolution de la mobilité résidentielle est-elle paradoxale ?. Économie publique/Public economics (20). 59

Lancaster T. 2000. The incidental parameter problem since 1948. Journal of Econometrics 95: 391-413. 51 
LEDa-LEGOS, CES 2012. Enquête Territoire - APA et tarification des services d'aide à domicile. Agnès Gramain and Jérôme Wittwer (dir.).

URL: http://www.modapa.cnrs.fr/index $n$ g.htmldemarche.donnees 4, 40, 52

Manning W. G., Newhouse J. P., Duan N., Keeler E. B., Leibowitz A., Maquis S. M. 1987. Health insurance and the demand for medical care: Evidence from a randomized experiment. American Economic Review 77(3): 251-77. 16

Messaoudi D. 2012. La différenciation qualitative dans les services de laide à domicile : une lecture par les conventions de qualité. Revue d'économie industrielle (138): 65-91. 40

Moffitt R. 1986. The econometrics of piecewise-linear budget constraints: A survey and exposition of the maximum likelihood method. Journal of Business $\&$ Economic Statistics 4(3): 317-328. 4, 5, 34, 36

Moffitt R. 1990. The econometrics of kinked budget constraints. The Journal of Economic Perspectives 4(2): 119-139. 5

Moulton B. R. 1990. An illustration of a pitfall in estimating the effects of aggregate variables on micro units. The Review of Economics and Statistics 72(2): 334-338. 12, 51

OECD 2013. OECD framework for statistics on the distribution of household income, consumption and wealth. OECD Publishing edn. Organisation for Economics Co-operation and Development. Paris. 31

Pezzin L. E., Kemper P., Reschovsky J. 1996. Does publicly provided home care substitute for family care? Experimental evidence with endogenous living arrangements. The Journal of Human Resources 31(3): 650-676. 2

Poletti B. 2012. Mission relative aux difficultés financières de laide à domicile et aux modalités de tarification et dallocation de ressources des services daide à domicile pour publics fragiles. Mission confiée par Madame Roselyne Bachelot-Narquin, Ministre des Solidarités et de la Cohésion Sociale. 42

Rapp T., Chauvin P., Sirven N. 2015. Are public subsidies effective to reduce emergency care? Evidence from the PLASA study. Social Science \& Medicine 138: 31-37. 1

Rapp T., Grand A., Cantet C., Andrieu S., Coley N., Portet F., Vellas B. 2011. Public financial support receipt and non-medical resource utilization in Alzheimers disease results from the PLASA study. Social Science \& Medicine 72(8): 1310-1316. 2

Sieurin A., Cambois E., Robine J.-M. 2011. Les espérances de vie sans incapacité en France: une tendance récente moins favorable que dans le passé. Document de travail 170. Ined. URL: http://www.cor-retraites.fr/IMG/pdf/doc-2234.pdf 1

Solard G. 2015. Les retraités et les retraites - Edition 2015. Collection Etudes et Statistiques. Drees. 1

Stabile M., Laporte A., Coyte P. C. 2006. Household responses to public home care programs. Journal of Health Economics 25(4): 674-701. 1, 2 
Staiger D., Stock J. H. 1997. Instrumental variables regression with weak instruments. Econometrica 65(3): 557-586. 11

Van Houtven C. H., Norton E. C. 2004. Informal care and health care use of older adults. Journal of Health Economics 23(6): 1159-1180. 17

Vanlerenberghe J.-M., Watrin D. 2014. Rapport d'information fait au nom de la commission des affaires sociales sur laide à domicile. Rapport d'information 575. Sénat. 11, 42

Zeckhauser R. 1970. Medical insurance: A case study of the tradeoff between risk spreading and appropriate incentives. Journal of Economic Theory 2(1): 10-26. 1

Zhen C., Finkelstein E. A., Nonnemaker J., Karns S., Todd J. E. 2014. Predicting the effects of sugar-sweetened beverage taxes on food and beverage demand in a large demand system. American Journal of Agricultural Economics 96(1): 1-25. 10 


\section{A ADDITIONAL INFORMATION ON THE DATA}

\section{A.1 Comparison of the department studied with metropoli- tan France}

Table A.I compares the department studied to metropolitan France. We use either administrative sources ([A]: Insee et al. (2013); [B]: Insee (2014); [D]: Drees (2013)) or survey data ([C]: Insee-Drees (2014)).

Column [1] gives descriptive statistics on metropolitan France while Column [2] focuses on the department studied. Column [2] reports intervals around the true department value to preserve its anonymity. Bounds are computed so that $20 \%$ of the French departments closest to the department of interest (weighting by the size of the departmental population aged 60 or more) have a value lying in the interval. ${ }^{27}$ If the department is located in the bottom quintile, we report as a lower bound the minimum value observed across French departments for the variable; similarly, when the department ranks in the top quintile, the upper bound we report is the maximum value observed in metropolitan France.

The third column tests the significance of the differences between the first two columns. For statistics computed using exhaustive administrative sources $([\mathrm{A}],[\mathrm{B}]$ and $[\mathrm{D}])$, we test whether the department population can be considered as a random draw from the French metropolitan population. When using survey data $([\mathrm{C}])$, the tests of difference compare the sample of the respondents of the department with the respondents of the rest of France.

Although differences are quasi-systematic in statistical terms, the selected department has socio-demographic characteristics close to that of France overall. Our selected department is however richer than the rest of France: it has a higher share of households subject to the income tax and a lower poverty rate in the $75+$ population, although the median taxable income in the department is only slightly higher than in France. Albeit the prevalence of functional limitations in the $60+$ population is similar in the department and in the rest of France, the rate of APA beneficiaries is slightly higher in our department. This possibly reflects local variations in the way the APA policy

\footnotetext{
${ }^{27}$ Insee et al. (2013) directly provides the deciles of the taxable income distribution in the metropolitan French population aged 75 or more. The department is found to be richer than the $40 \%$ least wealthy departments, but poorer than the $40 \%$ richest departments. We use the $4^{\text {th }}$ and $6^{\text {th }}$ deciles of the national distribution to bound the median taxable income observed in the department studied.
} 
is implemented (Billaud et al., 2012).

Table A.I: Descriptive statistics for department studied and metropolitan France

\begin{tabular}{|c|c|c|c|c|}
\hline & $\begin{array}{l}\text { Metropolitan } \\
\text { France }\end{array}$ & Department & $\begin{array}{l}\text { Difference } \\
\text { (p. value) }\end{array}$ & Source \\
\hline Variable & {$[1]$} & {$[2]$} & {$[1]-[2]$} & - \\
\hline \multicolumn{5}{|l|}{ General population } \\
\hline Households subject to income tax & $58.2 \%$ & {$[61.9 \%-75.1 \%]$} & 0.00 & {$[\mathrm{~A}]$} \\
\hline $60+$ population/total population & $24.4 \%$ & {$[23.8 \%-26.3 \%]$} & 0.00 & [B] \\
\hline \multicolumn{5}{|l|}{ Elderly population $(60+)$} \\
\hline $\begin{array}{l}\text { Average age } \\
\text { Health status (functional limitations) } \\
\text { Level } 1 \text { (least severe) } \\
\text { Level } 2 \\
\text { Level } 3 \\
\text { Level } 4 \text { (most severe) }\end{array}$ & $\begin{array}{c}71.8 \\
\\
64.9 \% \\
21.4 \% \\
7.7 \% \\
6.0 \% \\
100 \% \\
\end{array}$ & $\begin{array}{c}{[71.3-71.7]} \\
{[63.9 \%-66.2 \%]} \\
{[20.1 \%-21.0 \%]} \\
{[7.2 \%-7.8 \%]} \\
{[6.3 \%-7.0 \%]} \\
100 \%\end{array}$ & 0.00 & {$[\mathrm{C}]$} \\
\hline $\begin{array}{l}\text { Poverty rate in } 75+\text { population } \\
\text { Median taxable income }(75+\text { households })\end{array}$ & $\begin{array}{rl} & 8.9 \% \\
€ & 19,536 \\
\end{array}$ & $\begin{array}{c}{[6.9 \%-7.9 \%]} \\
{[€ 17,380-€ 22,050]}\end{array}$ & $\begin{array}{l}0.00 \\
\text { n.c. }\end{array}$ & {$[\mathrm{A}]$} \\
\hline $\begin{array}{l}\text { Rate of APA beneficiaries } \\
\text { At-home recipients/all APA beneficiaries }\end{array}$ & $\begin{array}{l}7.8 \% \\
58.7 \%\end{array}$ & $\begin{array}{c}{[8.1 \%-9.1 \%]} \\
{[56.1 \%-60.6 \%]}\end{array}$ & $\begin{array}{l}0.00 \\
0.00\end{array}$ & {$[\mathrm{D}]$} \\
\hline \multicolumn{5}{|l|}{ At-home APA beneficiaries } \\
\hline $\begin{array}{l}\text { Woman } \\
\text { Age groups } \\
\text { Age } 60-74 \\
\text { Age } 75-79 \\
\text { Age } 80-84 \\
\text { Age } 85+\end{array}$ & $\begin{array}{l}73.7 \% \\
12.7 \% \\
13.6 \% \\
23.9 \% \\
49.7 \% \\
100 \% \\
\end{array}$ & $\begin{array}{c}{[71.7 \%-72.8 \%]} \\
{[11.2 \%-12.7 \%]} \\
{[13.8 \%-14.6 \%]} \\
{[23.5 \%-24.4 \%]} \\
{[49.2 \%-51.0 \%]} \\
100 \% \\
\end{array}$ & 0.00 & {$[\mathrm{D}]$} \\
\hline $\begin{array}{l}\text { Living arrangements } \\
\text { Living alone } \\
\text { Living with her spouse } \\
\text { Living with a relative other than } \\
\text { her spouse }\end{array}$ & $\begin{array}{l}55.3 \% \\
30.4 \% \\
14.3 \% \\
100 \% \\
\end{array}$ & $\begin{array}{c}{[54.7 \%-56.9 \%]} \\
{[27.7 \%-32.7 \%]} \\
{[9.5 \%-12.5 \%]} \\
100 \%\end{array}$ & 0.88 & {$[\mathrm{C}]$} \\
\hline $\begin{array}{l}\text { Disability level } \\
\text { Disability level } 1 \text { (most severe) } \\
\text { Disability level } 2 \\
\text { Disability level } 3 \\
\text { Disability level } 4 \text { (least severe) }\end{array}$ & $\begin{array}{l}2.4 \% \\
16.8 \% \\
22.1 \% \\
58.8 \% \\
100 \%\end{array}$ & $\begin{array}{c}{[1.7 \%-2.1 \%]} \\
{[14.1 \%-15.6 \%]} \\
{[20.0 \%-21.7 \%]} \\
{[60.5 \%-64.5 \%]} \\
100 \%\end{array}$ & n.c. & {$[\mathrm{D}]$} \\
\hline Amount of effective subsidies & $€ 361.1$ & [€329.1-€350.5] & n.c. & \\
\hline
\end{tabular}

SourCES: [A]: Insee et al. (2013); [B]: Insee (2014); [C]: Insee-Drees (2014) - APA benefit is self-declared. Rate of spousal co-residence may be underestimated; [D]: Drees (2013)- Administrative files on APA beneficiaries in 2013, all French departments. Decomposition by sex and age (resp. by disability level) not available in 21 (resp. in 5) departments.

NotEs: Column [2] reports intervals around the true department value to preserve its anonymity. Bounds are computed so that $20 \%$ of the French departments closest to the department of interest (weighting by the size of the departmental population aged 60 or more) have a value lying in the interval.

TESTS: n.c. stands for "not computable". Test performed is a Student (resp. a Pearson $\chi^{2}$ ) test for binary (resp. categorical) variables. 


\section{A.2 Sample selection}

This Appendix aims at documenting the selection steps the data from October 2014 have gone through. We follow the same steps to construct the samples of October 2012 and 2013. The percentages of individuals selected at each step are very similar to what is found for 2014 and are available upon request.

The initial number of beneficiaries is considered to be $5,486 .{ }^{28}$ Table A.II sums up the selection steps.

Table A.II: Sample selection steps

\begin{tabular}{|c|c|c|c|c|c|c|}
\hline & \multirow{5}{*}{$\begin{array}{l}\text { All } \\
\text { (1) }\end{array}$} & \multicolumn{5}{|c|}{ Recipients with an authorized provider at least } \\
\hline & & \multirow{4}{*}{$\begin{array}{l}\text { All } \\
(2)\end{array}$} & \multicolumn{4}{|c|}{ Recipients effectively consuming care in the month } \\
\hline & & & \multirow{3}{*}{$\begin{array}{l}\text { All } \\
(3)\end{array}$} & \multicolumn{3}{|c|}{ "Stable" recipients } \\
\hline & & & & \multirow{2}{*}{$\begin{array}{l}\text { All } \\
(4)\end{array}$} & \multicolumn{2}{|c|}{$\begin{array}{l}\text { Recipients consuming only from } \\
\text { one authorized provider }\end{array}$} \\
\hline & & & & & $\begin{array}{l}\text { All } \\
(5)\end{array}$ & $\begin{array}{c}\text { Recipients with } \\
0<c_{i}<90 \% \\
(6)\end{array}$ \\
\hline Number & 5,486 & 4,475 & 4,199 & 3,527 & 3,327 & 2,862 \\
\hline$\%$ of previous step & - & $81.6 \%$ & $93.8 \%$ & $84.0 \%$ & $94.3 \%$ & $86.1 \%$ \\
\hline$\%$ of initial sample & $100 \%$ & $81.6 \%$ & $76.5 \%$ & $64.3 \%$ & $60.6 \%$ & $52.2 \%$ \\
\hline
\end{tabular}

NOTES: "Stable" APA recipients in October 2014 are defined as those for which information is available also for the months of September and November 2014. For additional 63 individuals (not in the numbers here above), the administrative files contain no information on the co-payment rate or or the consumption of home care hours, or are inconsistent with national APA legislation.

To observe precisely both the out-of-pocket price and the number of hours that are effectively consumed and subsidized, we retain the beneficiaries receiving care from an authorized provider. They represent the majority of APA recipients in the department (more than $4 / 5$ ).

Among them, about $6 \%$ have no actual consumption of home care recorded in the files. This might be explained by temporary absences (like hospitalizations) or disruptions (e.g. visits from relatives, who replace temporarily professional home care services by providing informal care). As the outcome of interest is missing, we drop these observations. Another $15 \%$ of APA recip-

\footnotetext{
${ }^{28}$ For October 2014, administrative records indicate that 5,549 beneficiaries were receiving APA; but for 61 individuals, essential information on subsidized hours, co-payment rate or on matrimonial status was missing or inconsistent. These individuals are presumably former APA recipients not yet erased from the files. For 2 additional individuals, the monetary value of the care plan was beyond the national legal ceiling, signaling a probable error in the records. We dropped these 63 observations from our sample.
} 
ients with an authorized provider have missing information on subsidized care consumption for the preceding or the following month. We choose to drop them to avoid potential unobservable shocks likely to bias our estimations. The remaining individuals can be regarded as "stable".

Among beneficiaries actually receiving care from an authorized provider at least, less than $6 \%$ receive care from a secondary provider. ${ }^{29}$ As we generally do not observe care consumption from the secondary provider nor its price, ${ }^{30}$ we drop multiple-provider individuals.

Beneficiaries with income below a certain threshold have a $0 \%$ co-payment rate: their OOP price is zero. Our log-log specification cannot be estimated on these observations. In addition, so as to make the relationship between the consumer price and the provider price fully linear in disposable income (see Appendix B.1), we retain only those individuals with a co-payment rate strictly below $90 \%$. These two income groups represent respectively $12.7 \%$ and $1.3 \%$ of the remaining 3,327 beneficiaries.

We end up with a sample that represents $52 \%$ of total at-home APA recipients of the department.

A Heckman-type model would allow to take into account the selection of our sample on both observable and unobservable factors affecting the demand for home care. But we do not have any good instrument at hand to construct an estimator that would not entirely rely on a parametric assumption. We choose to estimate our parameters of interest directly on the selected sample. Such a choice imposes to remain cautious about the external validity of our estimates, as discussed in Section 5.3 of the paper.

\footnotetext{
${ }^{29}$ The majority of these beneficiaries receive additional care from an over-the-counter worker (see Section $\mathrm{E}$ for more details on the different types of home care providers). Over-the-counter workers are generally cheaper and more flexible than home care structures. 7 individuals receive home care from a second authorized provider. Theoretically, there might be a third case: beneficiaries could also complement the care provided by an authorized structure with care provided by a non-authorized structure. Our files do not allow us to identify such cases; we believe they are marginal, as care provision by nonauthorized structures is rare (only $6 \%$ of beneficiaries with no authorized provider receive home care from a non-authorized structure).

${ }^{30}$ Even if we had all necessary information, dealing with the simultaneity of consumption decisions would have made our empirical strategy considerably more complex.
} 


\section{A.3 Imputation of couples of APA beneficiaries}

The data we collected indicate when a beneficiary lives with a partner, but we do not directly know whether the partner also receives APA. Having an APA-recipient spouse may correlate with one's own home care consumption; failing to control for such a characteristic may bias our estimates.

To identify potential couples in our sample, we checked whether each individual could be matched with another recipient of the opposite sex, recorded as living with a spouse, with exactly the same income ${ }^{31}$ and residing in the same municipality. If two individuals match, we assume they belong to the same household: our estimations will control for the fact of having a spouse receiving APA.

The matching procedure may fail for individuals whose co-payment rate is $0 \%$. The reported disposable income is the same for all such individuals, be they actual spouses or not. The same pitfall applies for individuals whose co-payment rate is $90 \%$. In these cases, the Departmental Council simply records the lower or upper income threshold of the APA co-payment schedule. In October 2014, only 16 individuals were not matched for this reason. But all our estimations rely on the sample of individuals with a co-payment rate strictly between 0 and $90 \%$, for who the matching procedure is systematically successful.

\section{A.4 Descriptive statistics on the pooled sample}

Table A.III replicates Columns (3) and (4) of Table I of the paper, by presenting the descriptive statistics on the pooled sample (and not on the 2014 sample only).

The pooled sample we derive our baseline estimates from is an unbalanced panel. In this sample, $26 \%$ of beneficiaries are present all three waves; another $26 \%$ are present only in two waves; finally, $48 \%$ are only present in one wave. ${ }^{32}$ Focusing on the sample of beneficiaries in October 2014, we see that the longer the individual has been receiving APA, the older she is; this translates into a higher proportion of women, who have a longer life-expectancy, and a lower proportion of beneficiaries with a spouse alive among the beneficiaries present

\footnotetext{
${ }^{31}$ The APA co-payment schedule takes into account the household income. See Appendix B.1.

${ }^{32}$ This does not mean that the typical APA recipient benefits from the scheme less than one year. For individuals observed only in 2012, for example, we do not know whether they were receiving APA one year or two years before. Average duration of APA benefits is estimated to be around 4 years (Debout, 2010).
} 
Table A.III: Descriptive statistics on the pooled sample (2012-2014)

\begin{tabular}{|c|c|c|}
\hline Variable & $\begin{array}{c}\text { Mean } \\
{[1]}\end{array}$ & $\begin{array}{c}\text { Std-dev. } \\
{[2]}\end{array}$ \\
\hline Care plan volume $[\mathrm{a}]$ & 20.9 & 10.7 \\
\hline Care plan monetary value $[\mathrm{b}]$ & $€ 456.1$ & $€ 235.8$ \\
\hline Hours effectively subsidized [c] & 18.1 & 10.8 \\
\hline Amount of effective subsidies $[\mathrm{d}]$ & $€ 303.1$ & $€ 199.2$ \\
\hline$[\mathrm{c}]$ inferior to $[\mathrm{a}]$ & $60.4 \%$ & - \\
\hline Ratio $[\mathrm{c}] /[\mathrm{a}]$ & $85.6 \%$ & 19.8pp. \\
\hline Ratio $[\mathrm{d}] /[\mathrm{b}]$ & $65.5 \%$ & $21.7 \mathrm{pp}$. \\
\hline Individualized income & $€ 1,301.5$ & $€ 415.6$ \\
\hline co-payment rate & $23.8 \%$ & $17.2 \mathrm{pp}$. \\
\hline Provider price & $€ 21.8$ & $€ 1.3$ \\
\hline OOP price & $€ 5.2$ & $€ 3.8$ \\
\hline $\begin{array}{l}\text { Total OOP payments } \\
\text { on subsidized hours }\end{array}$ & $€ 91.6$ & $€ 95.2$ \\
\hline Age & 84.0 & 7.3 \\
\hline Woman & $73.2 \%$ & - \\
\hline Disability level 1 & $1.2 \%$ & - \\
\hline Disability level 2 & $12.8 \%$ & - \\
\hline Disability level 3 & $20.2 \%$ & - \\
\hline Disability level 4 & $\begin{array}{l}65.8 \% \\
100 \%\end{array}$ & - \\
\hline Lives with a spouse & $33.8 \%$ & - \\
\hline Lives alone & $65.6 \%$ & - \\
\hline Spouse in institution & $\begin{array}{l}0.6 \% \\
100 \%\end{array}$ & - \\
\hline Number of individuals & 8,190 & - \\
\hline
\end{tabular}

in two or three waves. Those beneficiaries tend to be more disabled; they have, on average, a higher care plan volume and a higher number of hours subsidized by the APA scheme (consumption relative to the care plan volume being also higher). On the contrary, we do not see any difference in average provider and OOP prices, nor in income.

When using the unbalanced sample, we do not select a specific population - the new entrants into the APA scheme -; the shortcoming of such a choice, however, is that the individuals who have been present in several waves weigh more in the estimation than single-observation individuals. The cross-sectional estimates presented in Appendix G.1 show that the magnitude of the price elasticity estimate does not change substantially when replicating our estimations using the sample of beneficiaries present in October of either 2012, 2013 or 2014. 


\section{B SPECIFICATIONS}

\section{B.1 Addressing income and co-payment rate issues in the empirical specifications}

In Section 4.2 of the paper, when taking the absolute consumption as the dependent variable, our econometric specification is stated as follows:

$$
\ln \left(h_{i t}^{*}\right)=\gamma_{0}+\beta_{1} \cdot \ln \left(p_{i t}^{j}\right)+\left(\beta_{1}+\beta_{2}\right) \cdot \ln \left(I_{i t}\right)+X_{i t}^{\prime} \cdot \theta+\lambda_{t}+\epsilon_{i t}
$$

To ensure a clean identification of the parameters, two features of the data must be taken into account. First, the disposable income recorded in the data at time $t$ is not the current value of income but the income when the co-payment rate was computed or last revised, denoted $I_{i t}^{o b s}$. We express disposable income at time $t$ as: $I_{i t}=\rho_{i t} I_{i t}^{o b s}$, with $\rho_{i t}$ the rate of increase of individual disposable income between time $t$ and the year $i$ 's last co-payment rate was computed. As the rate of increase in disposable income $\rho_{i t}$ is not directly observable, we include a dummy $\mathbb{1}_{i t}^{d}$ equal to one when $i$ 's co-payment rate (observed in $t$ ) was last revised in year $d$. Dummy coefficients should capture the rate of increase in income between years $d$ and $t .{ }^{33}$ In our data, most co-payment rates were last computed between 2010 and 2014; for a few observations though, the latest computation of the co-payment rate is older $(d=2002, \ldots, 2014)$.

Second, the co-payment rate is set to be strictly proportional to the disposable income at the time the latest personalized care plan was defined, $I_{i t}^{o b s}$, according to the following function:

$$
c_{i t}=\frac{0.9}{2 M T P_{i t}^{D}} I_{i t}^{o b s}
$$

where $M T P_{i t}^{D}$ is the value of a particular disability allowance (Majoration pour Tierce-Personne) the year the co-payment rate was last computed for individual $i$ observed at time $t$. For a given observed income, the co-payment might differ according to the year $d$ when the co-payment rate was last computed. Year dummies $\mathbb{1}_{i t}^{d}, d=2002, \ldots, 2014$ thus additionally control for

\footnotetext{
${ }^{33}$ We implicitly assume the rate of increase in disposable income to be identical for two individuals observed a given year, whose personalized plans were decided upon the same year $d$. Retirees' income is mostly made of pension benefits (Deloffre, 2009), which are reevaluated every year following the inflation rate. It remains a strong assumption given the heterogeneity in income composition across the income distribution.
} 
inter-individual and intra-individual variation in this parameter.

For $2 \%$ of our sample, the relationship between the income and the copayment rate does not respect the legal formula used to compute the copayment rate. After a careful examination of the data, we hypothesize that most of these errors occurred when the co-payment rate was computed; conversely, we assume the values of income and co-payment rate are well recorded. We add a dummy variable $\mathbb{1}_{i t}^{e}$ signaling whether the observation is affected by such a calculation error. The full equation to be estimated is then:

$$
\ln \left(h_{i t}^{*}\right)=\gamma_{0}+\beta_{1} \cdot \ln \left(p_{i t}^{j}\right)+\left(\beta_{1}+\beta_{2}\right) \cdot \ln \left(I_{i t}^{o b s}\right)+\sum_{d=2002}^{2014} \xi^{d} \cdot \mathbb{1}_{i t}^{d}+\zeta \cdot \mathbb{1}_{i t}^{e}+X_{i t}^{\prime} \cdot \theta+\epsilon_{i t}
$$

Finally, note that our econometric specification includes disposable income and not income per se. In the APA scheme, disposable income is defined as the individualized income ${ }^{34}$ minus an amount equal to $0.67 \times \operatorname{MTP}_{i t}^{D}(€ 739$ per month for an individual whose income and co-payment rate was last reassessed in 2014). It roughly equals the old-age minimum income allowance. This amount may be regarded as the minimum income that will ensure the individual can satisfy her basic consumption needs: the individual trades off home care consumption for other consumption goods only when deciding upon the allocation of the part of her income in excess of the minimum income allowance.

\section{B.2 Specification with relative consumption}

When using the specification with relative consumption, we consider as the dependent variable the share of the care plan that is effectively consumed by the individual, $h_{i t}^{*} / \bar{h}_{i t}$ (this is the ratio we call the "relative consumption").

Empirically, we take the log of the ratio and estimate the following speci-

\footnotetext{
${ }^{34}$ Individualized income equals the individual's monetary income when the beneficiary has no spouse alive; it is equal to the household monetary income divided by 1.7 when the beneficiary has a spouse alive. The consumption unit attributed to the second adult of the household follows the Oxford (or "old OECD") scale (OECD, 2013). Compared to the OECD-modified scale, which is nowadays the most frequently used in France, the use of the Oxford scale to compute APA individualized income implies that the economies of scale in a household with a disabled elderly are lower than in other households.
} 
fication:

$$
\begin{aligned}
\ln \left(h_{i t}^{*} / h_{i t}^{-}\right) & =\tilde{\gamma}_{0}+\tilde{\beta}_{1} \cdot \ln \left(p_{i t}^{j}\right)+\left(\tilde{\beta}_{1}+\tilde{\beta}_{2}\right) \ln \left(I_{i t}^{o b s}\right)+\beta_{3} \cdot \ln \left(\bar{h}_{i t}\right) \\
& +\sum_{d=2002}^{2014} \tilde{\xi}^{d} \cdot \mathbb{1}_{i t}^{d}+\tilde{\zeta} \cdot \mathbb{1}_{i t}^{e}+X_{i t}^{\prime} \cdot \tilde{\theta}+\tilde{\lambda}_{t}+\tilde{\epsilon}_{i t}
\end{aligned}
$$

The dependent variable is still censored when individuals fully consume their care plan volume (exact volume or more), but the censoring point now equals $\ln \left(h_{i t}^{*} / \bar{h}_{i t}\right)=\ln (1)=0$. It is the same for all beneficiaries, whatever the volume of the care plan. Equation (9) is equivalent to:

$$
\begin{aligned}
\ln \left(h_{i t}^{*}\right)-\ln \left(\overline{h_{i t}}\right) & =\tilde{\gamma}_{0}+\tilde{\beta}_{1} \cdot \ln \left(p_{i t}^{j}\right)+\left(\tilde{\beta}_{1}+\tilde{\beta}_{2}\right) \ln \left(I_{i t}^{o b s}\right)+\tilde{\beta}_{3} \cdot \ln \left(\overline{h_{i t}}\right) \\
& +\sum_{d=2002}^{2014} \tilde{\xi}^{d} \cdot \mathbb{1}_{i t}^{d}+\tilde{\zeta} \cdot \mathbb{1}_{i t}^{e}+X_{i t}^{\prime} \cdot \tilde{\theta}+\tilde{\lambda}_{t}+\tilde{\epsilon}_{i t} \\
\ln \left(h_{i}^{*}\right) & =\tilde{\gamma}_{0}+\tilde{\beta}_{1} \cdot \ln \left(p_{i t}^{j}\right)+\left(\tilde{\beta}_{1}+\tilde{\beta}_{2}\right) \ln \left(I_{i t}^{o b s}\right)+\left(\tilde{\beta}_{3}+1\right) \cdot \ln \left(\bar{h}_{i t}\right) \\
& +\sum_{d=2002}^{2014} \tilde{\xi}^{d} \cdot \mathbb{1}_{i t}^{d}+\tilde{\zeta} \cdot \mathbb{1}_{i t}^{e}+X_{i t}^{\prime} \cdot \tilde{\theta}+\tilde{\lambda}_{t}+\tilde{\epsilon}_{i t}
\end{aligned}
$$

In Equation (9), $\tilde{\beta}_{1}$ can thus be interpreted as the price elasticity of demand. The equation presented in the previous section, Equation (8), is nested in this equation. It would be equivalent to Equation (10) if we imposed the constraint that $\tilde{\beta}_{3}=-1$.

The specification with relative consumption comes with several advantages. First, it includes the care plan volume as a control, which might be a proxy of the unobserved determinants of consumption. Second, relative consumption is a better-behaved outcome than absolute consumption: its distribution is closer to a normal (Figures B.1 and B.2) and the consistency of Tobit estimates requires the normality of the error term. Finally, it enables us to overcome the limitation of having an individual-specific censoring point: it eases the implementation of the estimations.

[Figures B.1 and B.2 to be found on the following page] 
Figure B.1: Distribution of absolute home care consumption, by disability level

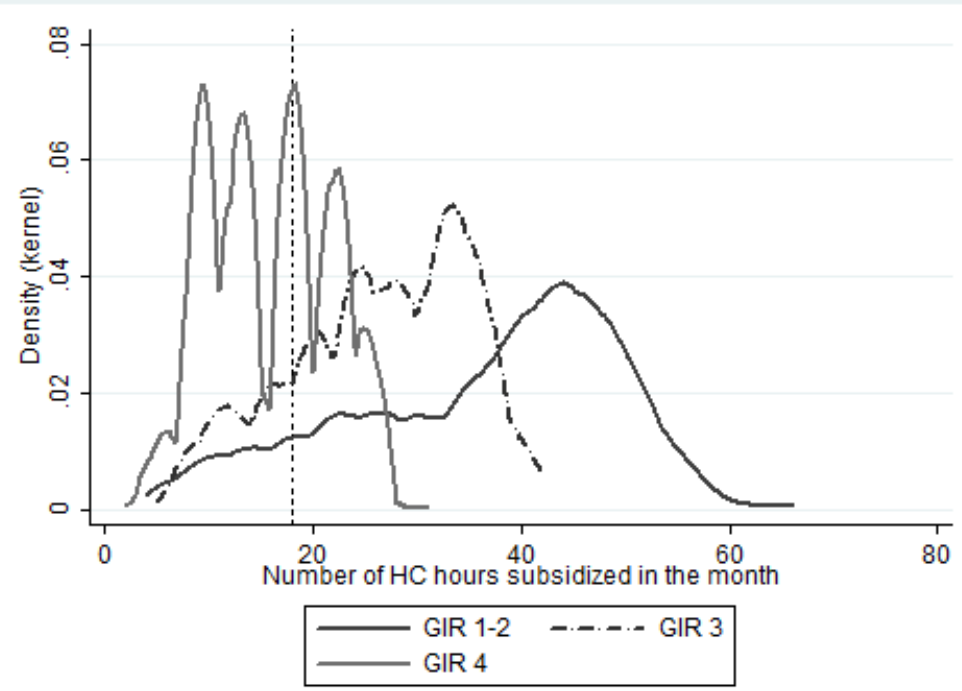

SAMPLE: Estimation sample (data from October 2012, 2013 and 2014; 8,190 individuals). Sub-sample size: $\mathrm{N}=1,145$ in GIR 1 or 2 (most severe disability levels); $\mathrm{N}=1,655$ in GIR $3 ; \mathrm{N}=5,390$ in GIR 4 (least severe disability level).

Notes: The "GIR" corresponds to the official disability level of APA beneficiaries. The dashed vertical line indicates the pooled sample median value of home care consumption.

Figure B.2: Distribution of relative home care consumption, by disability level

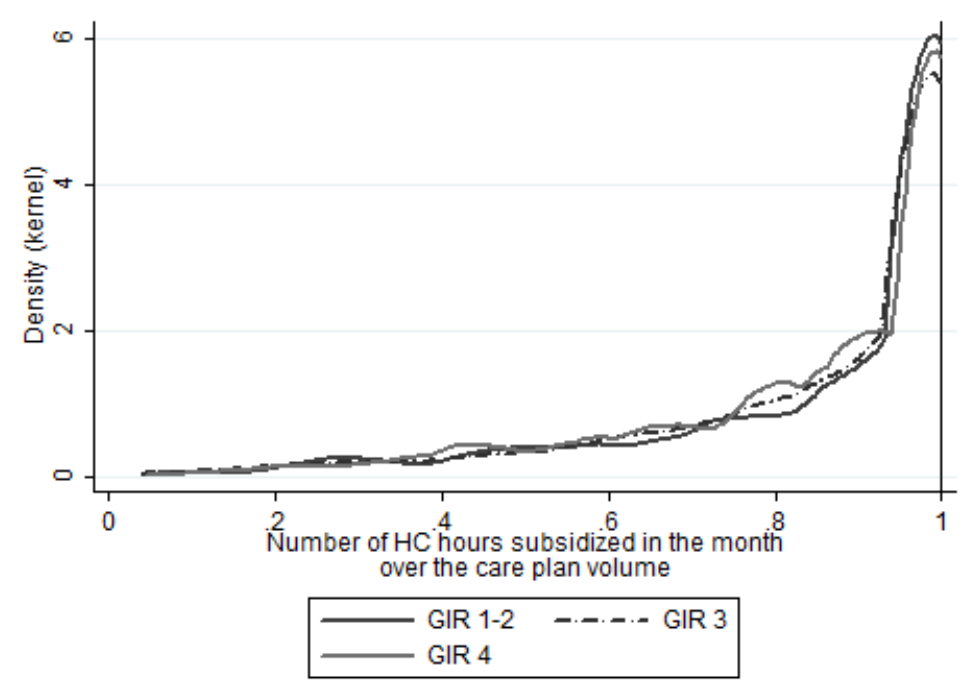

SAMPLE: Estimation sample (data from October 2012, 2013 and 2014; 8,190 individuals). Sub-sample size: $\mathrm{N}=1,145$ in GIR 1 or 2 (most severe disability levels); $\mathrm{N}=1,655$ in GIR $3 ; \mathrm{N}=5,390$ in GIR 4 (least severe disability level).

Notes: Relative home care consumption designates the ratio $h_{i} / \bar{h}_{i}$. The "GIR" corresponds to the official disability level of APA beneficiaries. The solid vertical line at 1 indicates the censoring point of relative consumption. 


\section{MAXIMUM LIKELIHOOD ESTIMATION}

The objective of this appendix is twofold. First, it provides the expression of the likelihood function we maximize to derive our baseline estimates (Tobit estimation). Second, it shows that, within the framework proposed by Moffitt (1986), the censoring of the measure of consumption at the kink and beyond does not prevent the identification of the sample average price elasticity of demand, conditional on some assumptions on the stability of individual preferences.

To keep notations simple and concise, we ignore the time dimension (subscript $t$ and year dummies are not included) and consider home care consumption in level when deriving the likelihood function (while we include its log in the empirical specification).

\section{C.1 General setting}

The demand for home care with the kinked budget constraint generated by APA writes:

$$
\begin{cases}h_{i}^{*}=g\left(c_{i} p_{i}, I_{i} ; X_{i}\right)+\nu_{i} & \text { if } h_{i}^{*}<\bar{h}_{i} \\ g\left(p_{i}, \tilde{I}_{i} ; X_{i}\right)+\nu_{i} \leq \bar{h}_{i} \leq g\left(c_{i} p_{i}, I_{i} ; X_{i}\right)+\nu_{i} & \text { if } h_{i}^{*}=\bar{h}_{i} \\ h_{i}^{*}=g\left(p_{i}, \tilde{I}_{i} ; X_{i}\right)+\nu_{i} & \text { if } h_{i}^{*}>\bar{h}_{i}\end{cases}
$$

with $\nu_{i}$ an individual preference shifter. We denote:

$\psi$ a set of parameters characterizing the function $g($.$) ;$

$\kappa$ a set of parameters characterizing the distribution of the error term $\nu$;

$S_{1}$ the left-hand side segment of the budget constraint: $i \in S_{1} \Longleftrightarrow h_{i}^{*}<\bar{h}_{i}$; $S_{2}$ the right-hand side segment of the budget constraint: $i \in S_{2} \Longleftrightarrow h_{i}^{*}>\bar{h}_{i}$; $K$ the kink of the budget constraint: $i \in K \Longleftrightarrow h_{i}^{*}=\bar{h}_{i}$.

\section{C.2 Observational scheme with censoring}

With $h_{i}$ the consumption in the data and $h_{i}^{*}$ the true consumption, our observational scheme is:

$$
h_{i}= \begin{cases}h_{i}^{*} & \text { if } h_{i}^{*}<\bar{h}_{i} \\ \bar{h}_{i} & \text { if } h_{i}^{*} \geq \bar{h}_{i}\end{cases}
$$

From Systems 11 and 12, we know that: 
1. For all individuals $i$ such that $h_{i}<\bar{h}_{i}$, we know that $h_{i}=h_{i}^{*}$; thus we have $h_{i}^{*}<\bar{h}_{i}\left(i \in S_{1}\right)$ :

$$
h_{i}=g\left(c_{i} p_{i}, I_{i} ; X_{i}\right)+\nu_{i}<\bar{h}_{i}
$$

2. For individuals $i$ such that $h_{i}=\bar{h}_{i}$, we know that $h_{i}^{*} \geq \bar{h}_{i}$; these individuals can be split in two different sub-groups:

(a) Individuals $i$ such that $h_{i}^{*}=\bar{h}_{i}(i \in K)$; then:

$$
\left\{\begin{array}{l}
g\left(c_{i} p_{i}, I_{i} ; X_{i}\right)+\nu_{i} \geq \bar{h}_{i} \\
g\left(p_{i}, \tilde{I}_{i} ; X_{i}\right)+\nu_{i} \leq \bar{h}_{i}
\end{array}\right.
$$

(b) Individuals $i$ such that $h_{i}^{*}>\bar{h}_{i}\left(i \in S_{2}\right)$; then:

$$
\left\{\begin{array}{l}
g\left(c_{i} p_{i}, I_{i} ; X_{i}\right)+\nu_{i}>\bar{h}_{i} \\
g\left(p_{i}, \tilde{I}_{i} ; X_{i}\right)+\nu_{i}>\bar{h}_{i}
\end{array}\right.
$$

Thus, all censored observations $\left(i \in S_{2}\right.$ or $i \in K$ ) have in common the fact that:

$$
g\left(c_{i} p_{i}, I_{i} ; X_{i}\right)+\nu_{i} \geq \bar{h}_{i}
$$

We can thus write:

$$
h_{i}= \begin{cases}g\left(c_{i} p_{i}, I_{i} ; X_{i}\right)+\nu_{i} & \text { if } g\left(c_{i} p_{i}, I_{i} ; X_{i}\right)+\nu_{i}<\bar{h}_{i} \\ \bar{h}_{i} & \text { if } g\left(c_{i} p_{i}, I_{i} ; X_{i}\right)+\nu_{i} \geq \bar{h}_{i}\end{cases}
$$

which corresponds to the usual censored regression model setting.

The individual contributions to the likelihood function are derived from this setting. Denote $f\left(. \mid c_{i}, p_{i}, I_{i}, \bar{h}_{i}, X_{i}\right)$ the conditional density function of $\nu$ and $F\left(. \mid c_{i}, p_{i}, I_{i}, \bar{h}_{i}, X_{i}\right)$ its conditional cumulative distribution function. Then the likelihood function writes:

$$
\begin{aligned}
L(\psi, \kappa) & =\prod_{i=1}^{n}\left[f\left(h_{i}-g\left(c_{i} p_{i}, I_{i} ; X_{i}\right) \mid c_{i}, p_{i}, I_{i}, \bar{h}_{i}, X_{i}\right)\right]^{\mathbb{I}_{\left[h_{i}<\bar{h}_{i}\right]}} \\
& \times\left[\left(1-F\left(\bar{h}_{i}-g\left(c_{i} p_{i}, I_{i} ; X_{i}\right) \mid c_{i}, p_{i}, I_{i}, \bar{h}_{i}, X_{i}\right)\right)\right]^{\mathbb{I}\left[h_{i}=\bar{h}_{i}\right]}
\end{aligned}
$$

In our setting, the censoring of the dependent variable exactly at the kink prevents us from distinguishing between the individuals who consume exactly at the kink and those who actually locate on the right-hand side segment of the budget constraint. Interestingly, it does not prevent the identification of our 
parameters of interest (which relate to function $g($.$) ), although it comes at a$ cost in terms of precision. Assuming some stability of individual preferences, ${ }^{35}$ we can interpret the price elasticity estimated using information relating to the left-hand side of the kink as the price sensitivity of demand along the entire budget constraint.

Weaker assumptions on individual preferences would not undermine the identification of the price sensitivity for the selected sample of APA beneficiaries consuming less than their care plan volume. However, if the underlying data generating process actually changes at the kink, censored regression methods would not adequately correct for the bias induced by the non-observability of the individuals consuming at the kink or beyond.

\section{C.3 Likelihood of our sample}

As explained in Section 4.2 of the paper, we assumed the following specification for the demand for home care: ${ }^{36}$

$$
\ln \left(h_{i}^{*}\right)=\gamma_{0}+\beta_{1} \cdot \ln \left(p_{i}^{j}\right)+\left(\beta_{1}+\beta_{2}\right) \cdot \ln \left(I_{i}\right)+X_{i}^{\prime} \cdot \theta+\epsilon_{i}
$$

We assume a normal distribution for the idiosyncratic shock $\epsilon$ :

$$
\epsilon \mid p, I, X \sim \mathcal{N}\left(0, \sigma^{2}\right)
$$

Our likelihood function thus writes:

$$
\begin{aligned}
L(\beta, \gamma, \theta, \sigma) & =\prod_{i=1}^{n}\left[\frac{1}{\sigma} \phi\left(\frac{\ln \left(h_{i}\right)-\gamma_{0}-\beta_{1} \cdot \ln \left(p_{i}^{j}\right)-\left(\beta_{1}+\beta_{2}\right) \cdot \ln \left(I_{i}\right)-X_{i}^{\prime} \cdot \theta}{\sigma}\right)\right]^{\mathbb{I}\left[h_{i}<\bar{h}_{i}\right]} \\
& \times\left[\left(1-\Phi\left(\frac{\ln \left(\bar{h}_{i}\right)-\gamma_{0}-\beta_{1} \cdot \ln \left(p_{i}^{j}\right)-\left(\beta_{1}+\beta_{2}\right) \cdot \ln \left(I_{i}\right)-X_{i}^{\prime} \cdot \theta}{\sigma}\right)\right)\right]^{\mathbb{I}\left[h_{i}=\bar{h}_{i}\right]}
\end{aligned}
$$

where $\phi($.$) (resp. \Phi()$.$) the conditional density (resp. cumulative distribution)$ function of a standardized normal variable.

When using the specification with the relative consumption, we have:

$$
\ln \left(h_{i}^{*} / \bar{h}_{i}\right)=\tilde{\gamma}_{0}+\tilde{\beta}_{1} \cdot \ln \left(p_{i}^{j}\right)+\left(\tilde{\beta}_{1}+\tilde{\beta}_{2}\right) \cdot \ln \left(I_{i}\right)+\tilde{\beta}_{3} \cdot \ln \left(\bar{h}_{i}\right)+X_{i}^{\prime} \cdot \tilde{\theta}+\tilde{\epsilon}_{i}
$$

\footnotetext{
35 Moffitt (1986) assumes the functional form of $g($.$) is invariant to changes in consumer price and$ income.

${ }^{36}$ Again, for the sake simplicity, we do not include in the expressions provided in this Appendix the full set of dummies we actually include in our specifications to control for both the unobserved increase in income and the legal relationship between the co-payment rate and disposable income (see Appendix B.1).
} 
Similarly, we assume a normal distribution for the idiosyncratic shock $\tilde{\epsilon}$ :

$$
\tilde{\epsilon} \mid p, I, X, \bar{h} \sim \mathcal{N}\left(0, \tilde{\sigma}^{2}\right)
$$

The likelihood function writes:

$$
\begin{aligned}
\tilde{L}(\tilde{\beta}, \tilde{\gamma}, \tilde{\theta}, \tilde{\sigma}) & =\prod_{i=1}^{n}\left[\frac{1}{\tilde{\sigma}} \phi\left(\frac{\ln \left(h_{i}^{*} / \bar{h}_{i}\right)-\tilde{\gamma}_{0}-\tilde{\beta}_{1} \cdot \ln \left(p_{i}^{j}\right)-\left(\tilde{\beta}_{1}+\tilde{\beta}_{2}\right) \cdot \ln \left(I_{i}\right)-\tilde{\beta}_{3} \cdot \ln \left(\bar{h}_{i}\right)-X_{i}^{\prime} \cdot \tilde{\theta}}{\tilde{\sigma}}\right)\right]^{\mathbb{I}}\left[h_{i} / \overline{\left.h_{i}<1\right]}\right. \\
& \times\left[\left(1-\Phi\left(\frac{\ln \left(h_{i}^{*} / \bar{h}_{i}\right)-\tilde{\gamma}_{0}-\tilde{\beta}_{1} \cdot \ln \left(p_{i}^{j}\right)-\left(\tilde{\beta_{1}}+\tilde{\beta}_{2}\right) \cdot \ln \left(I_{i}\right)-\tilde{\beta}_{3} \cdot \ln \left(\bar{h}_{i}\right)-X_{i}^{\prime} \cdot \tilde{\theta}}{\tilde{\sigma}}\right)\right)\right]^{\mathbb{I}\left[h_{i} / \bar{h}_{i}=1\right]}
\end{aligned}
$$

Consistent estimators of $\beta_{1}, \beta_{2}$ and $\theta$ (respectively of $\tilde{\beta}_{1}, \tilde{\beta}_{2}, \tilde{\beta}_{3}$ and $\tilde{\theta}$ ) can be derived as the arguments of the maximization of the log-likelihood function, provided it is concave. ${ }^{37}$

In order to derive the likelihood function when taking the log-absolute consumption as the dependent variable, we must assume the censoring point $\bar{h}_{i}$ does not depend on the error term, $\epsilon_{i}$. In other words, the individual censoring point is assumed to be exogenous, conditional on the observable variables. This assumption is discussed in the next Section and is not needed when we take the log-relative consumption as the dependent variable.

\footnotetext{
${ }^{37}$ Similarly, though with a little more work, we could derive the likelihood function of the IV-Tobit model. In the version we estimate (using Stata command ivtobit), the error terms of the first-stage and second-stage equations are assumed to be jointly normally distributed.
} 


\section{DETERMINANTS OF THE CARE PLAN VOLUME AND CENSORING}

When taking the log-absolute consumption as the dependent variable, the Maximum Likelihood function (Appendix C) is derived assuming the individual censoring point, defined by $\bar{h}_{i}$, is exogenous conditional on explanatory variables. In addition, consistency of estimates relies on the additional assumption that the provider price $p_{i j}$ is exogenous. When estimating Equation (7) (Appendix B.1), one particular concern is that the provider price and the care plan volume are correlated even conditional on the control variables.

These two assumptions - exogeneity of the censoring point and no systematic conditional relationship between the care plan volume and the provider price - are relaxed when we take the log-relative consumption as the dependent variable. This Appendix nonetheless discusses the plausibility of these assumptions, by presenting elements on the establishing of the care plan volume and additional empirical material.

When setting the care plan volume $\bar{h}_{i}$, the evaluation team supposedly takes into account the needs of the beneficiary in terms of assistance with the activities of daily living. By law, the care plan volume should depend on the administrative disability group. Gender and age (which we control for) may influence the care plan volume, as they correlate with unobserved health problems and housekeeping skills. Additionally, even tough matrimonial status and family structure are not supposed to influence the care plan volume, anecdotal evidence suggests that the evaluation team takes into account the possible assistance regularly provided by relatives when establishing the care plan.

Additionally, $\bar{h}_{i}$ could directly relate to the price of the chosen provider in a specific case: when the evaluation team sets the personalized care plan, it has to check that the monetary equivalent of the care plan volume is below the legal ceiling associated with the disability level of the beneficiary. In the case care is provided by an authorized provider, the monetary equivalent of the care plan equals the number of hours granted by the evaluation team times the provider price. If the monetary equivalent of the care plan volume is higher than the legal ceiling, the adjustment will go through a reduction in $\bar{h}_{i}$ or the choice of a cheaper provider. This may be a source of price endogeneity in both (absolute and relative consumption) specifications. ${ }^{38}$

\footnotetext{
${ }^{38}$ Yet it should remain limited: for $7 \%$ of our sample at most, the monetary equivalent of their care
} 
Empirically, once controlling for income, gender, age, disability group, matrimonial status and professional care received on weekends, we find a small positive correlation between the (OOP or provider) price and the volume of the care plan, but the effect is not statistically significant. ${ }^{39}$ Then, a probit estimation of the probability to be censored, $\mathbb{P}\left(h_{i}=\bar{h}_{i}\right)$, shows that the probability to be censored slightly correlates with the price. $\mathrm{A} € 1$ increase in the provider price is predicted to increase the probability to be censored by 2 pp. (as a reminder, the sample censoring rate is around $40 \%$ and the standard-deviation in provider prices is of $€ 1.3$ ).

Although they are statistically significant, these effects are small in practical terms. In addition, they fade out when we restrict our attention to beneficiaries living in a municipality where only one provider is operating. This suggests that the strategic choice of a provider (price) to comply with the legal ceiling is empirically negligible in this sub-sample (see Appendix G.3).

The probability to be censored is higher for individuals with no partner at home, possibly because individuals living with a partner benefit from economies of scale in home care utilization ${ }^{40}$ and from informal help provided by their spouse. Consuming the care plan volume totally is also more likely for individuals who are entitled to subsidies on formal care served during the weekends.

Individual observable characteristics explain about $50 \%$ of the variations observed in the care plan volume. This leaves a large share of the variations unexplained. Ethnographic work suggests that unobserved informal care or health status can influence the evaluation team in the set up of the care plan volume (Billaud et al., 2012).

As we do not have any good instrument to test the endogenity of the care plan volume in our dataset, we have to rely on the assumption that it is reasonably exogenous when estimating the specification with log-absolute consumption as the dependent variable. This is one of the reasons why we favour the specification with the relative consumption (Equation (9), Appendix B.2).

plan volume would exceed their legal ceiling if they choose the most expensive provider operating in their municipality.

${ }^{39}$ In the panel analysis, we include fixed effects and cluster at the individual level. Table of results is not included but is available upon request.

${ }^{40}$ These economies of scale are not factored in by the evaluation team when setting the care plan volume. This is consistent with the fact that APA is meant to be a personal subsidy: legal ceilings do not depend on whether a beneficiary has a partner also receiving APA. 


\section{E THE HOME CARE SECTOR IN FRANCE}

\section{E.1 Three main types of home care providers}

Home care to the disabled elderly can be provided by three types of providers:

(1) Authorized structures (services autorisés), which must receive a special authorization granted by the Departmental Council to enter the market; their price is fixed by the Departmental Council.

(2) Non-authorized structures (services agréés non autorisés) are allowed to provide home care services to APA beneficiaries under lighter conditions than authorized structures; they are free to set their price (with some restrictions on yearly price evolution being set at the departmental level).

(3) Over-the-counter workers (gré-à-gré ou mandataire): the beneficiary directly contracts with a home care worker. The beneficiary is free to set her employee's hourly wage provided she complies with general labor law.

There is no regulation for over-the-counter workers. Both authorized and non-authorized structures have to meet quality standards, though requirements are higher for authorized structures. The existence of differences in quality between authorized providers is less clear-cut. From a theoretical prospective though, the uncertainties regarding the quality of services in the home care sector lead to rule out vertical differentiation through prices (Messaoudi, 2012).

In our empirical analysis, we focus on authorized providers: technically, we are able to compute the exact OOP price of their customers receiving APA as these services are priced by the Departmental Council. More broadly, APA subsidized professional care is mainly provided by this type of structure: using a survey conducted on the French departments (LEDa-LEGOS and CES, 2012), Hege et al. (2014) document that in over $45 \%$ of (responding) departments, more than two thirds of APA home care hours are provided by authorized services. Care provided by authorized structures represent less than one third of APA hours in only $15 \%$ of departments. ${ }^{41}$

\footnotetext{
${ }^{41}$ Using our data, we study the determinants of the choice of a provider. We find that individuals receiving care from an authorized provider are on average less rich than the overall population of APA beneficiaries; they tend to be younger, less disabled and live more often alone (results available upon request).
} 


\section{E.2 The different status for authorized providers}

Authorized providers can be either public, for-profit or non-profit. Historically, in France, non-profit organizations were important providers of home care and they remain predominant in most rural areas. In our department, 5 authorized providers are non-profit, providing care to about $54 \%$ of our estimation sample in October 2014. 20 municipal services are providing care to APA recipients (about $43 \%$ of the 2014 sample). For-profit structures represent a small share of the authorized home care providers (3 in the department), as they provide home care only to $3 \%$ of our 2014 sample. $^{42}$

Theoretically, an APA beneficiary is free to choose her provider. In practice, the spatial coverage by the different types of authorized services is unequal over the territory. In some municipalities, several providers are found to operate, while there is only one provider in others (see Section G.3). In our department, among the beneficiaries living in a municipality where several authorized providers serve APA recipients, more than $50 \%$ can choose between the three types of authorized providers. These beneficiaries live in relatively large municipalities: the supply mix is more diversified when there is an important market for home care services, while small municipalities are generally de facto served by a unique, non-profit structure. Conversely, the typical supply mix in medium-size municipalities is the combination of nonprofit and public authorized providers. Finally, a for-profit provider is never found to be the only authorized service operating in a given municipality.

\footnotetext{
${ }^{42}$ Proportions are similar in the pooled sample. The small market share of for-profit services among authorized providers is not a specific feature of the department studied.
} 


\section{F EXPLAINING VARIATIONS IN PROVIDER PRICES}

\section{F.1 Components of costs in the home care sector}

In this section, we explain why customers may exogenously face different provider prices, by detailing the components of prices in the home care sector.

Authorized providers are priced by the Departmental Council. The hourly price of each provider, for one given year, should be set on the basis of the overall average hourly production cost of the provider, of two years before. The various components of production costs are described in qualitative studies, either in academic works (Gramain and Xing, 2012) or in public reports. ${ }^{43}$ By order of importance (top-down), production costs can be decomposed as follows:

- Workforce costs (80\% of total charges): wages paid to professional caregivers and, for a small part (around 10\% of total charges), to the supervising staff. The wage of a caregiver depends on her qualification, according to collective labour agreements. We expect that the larger the proportion of skilled caregivers, the higher the production cost and the price. Wages are also augmented if employees work on Sunday or on public holidays, in accordance with general labour legislation.

- Operating costs (10-15\% of total charges): those include rents for the service's offices and other running expenses.

- Transportation costs (5-10\% of total charges) ${ }^{44}$ correspond to the compensation for the costs borne by employees to go to the consumer's home. This item is likely to vary largely across services according to their geographical area of intervention.

- Contrary to the health care sector, technological progress and capital costs are negligible in the home care sector.

We represent the relationship between the provider price and several providers' characteristics graphically. ${ }^{45}$ We distinguish between non-public (mainly non-

\footnotetext{
${ }^{43}$ There is, though, no national, comprehensive benchmark study on the costs of home care services. Public reports regularly deplore the lack of information on costs as a major shortcoming preventing from understanding the functioning of the sector (Vanlerenberghe and Watrin, 2014; Poletti, 2012).

${ }^{44}$ This item only includes the compensation of employees for the monetary costs associated with transport. The ongoing study mentioned in the paper additionally takes into account the unproductive hours spent on transports by the employees that are paid by the provider.

${ }^{45}$ We explore here other characteristics than the number of served municipalities, that we use as an instrument for the price. The empirical relationship between the two variables is documented by Figure
} 
profit) providers and public providers. The latest are likely to receive grants or advantages (e.g., a free office) from local municipalities that reduce operating costs. Such advantages are taken into account in the pricing process done by the Departmental Council and lower down the regulated price of public providers. In the graphical representation, we exclude the largest provider of the department, a nationwide non-profit organization, which has systematically the highest values for the variables we are here interested in (see Appendix ??)

In Figure F.1, provider prices are plotted against the number of APA beneficiaries served by the service. Graphically, the more customers the provider has, the higher its price. Having more customers might be associated with more municipalities to serve (see discussion in Section 4.4 of the paper) or more unproductive hours. ${ }^{46}$ This graph should be interpreted cautiously though: we only know the number of APA recipients served by each home care provider, instead of the total number of customers (including non-APA beneficiaries, like other elderly or disabled individuals) served in the department.

Figure F.2 shows the relationship between the provider price and the share of hours they serve on Sundays or on public holidays. Public providers have a very low share of such hours, as most public services do not operate on weekends and holidays. A higher share of hours made on holidays is associated with a higher price among public structures, which is consistent with the financial compensation of employees for working on public holidays.

[Table F.2 to be found on the following page]

2 in the paper.

${ }^{46}$ Unproductive hours (meetings, training) may become relatively more numerous when a service gets relatively large. 
Figure F.1: Provider price according to the number of APA beneficiaries served by the provider, by legal status

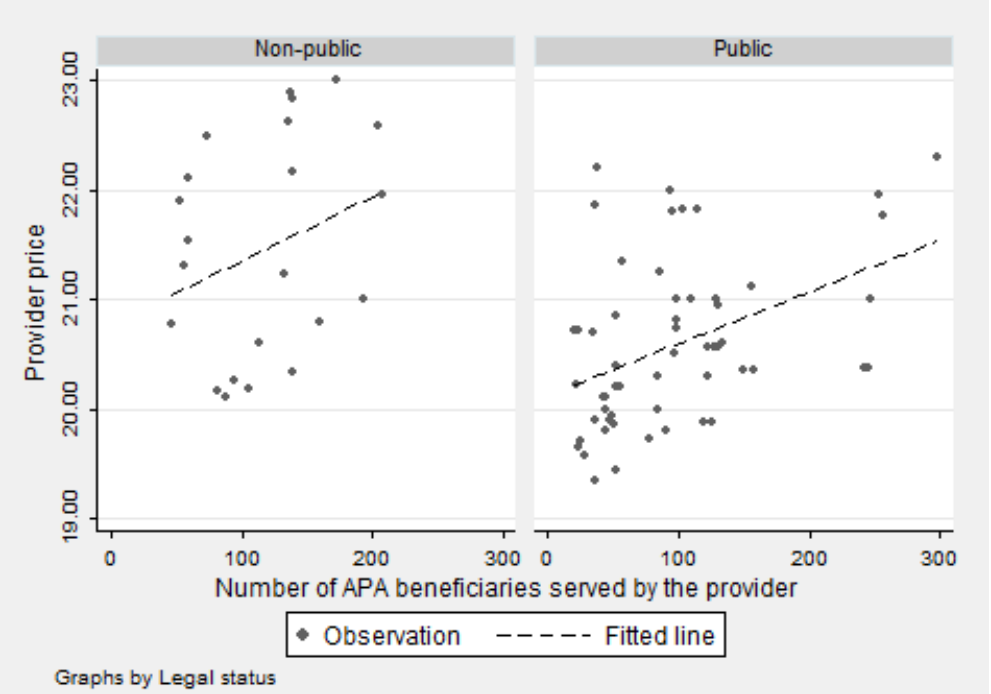

SAMPLE: Authorized providers of the department serving at least one APA beneficiary in October 2012, 2013 or 2014.

Notes: The largest provider, which serves $43 \%$ of the APA beneficiaries receiving care from an authorized provider in the department in 2014 , is not included.

Figure F.2: Provider price according to the share of hours served on Sundays and public holidays, by legal status

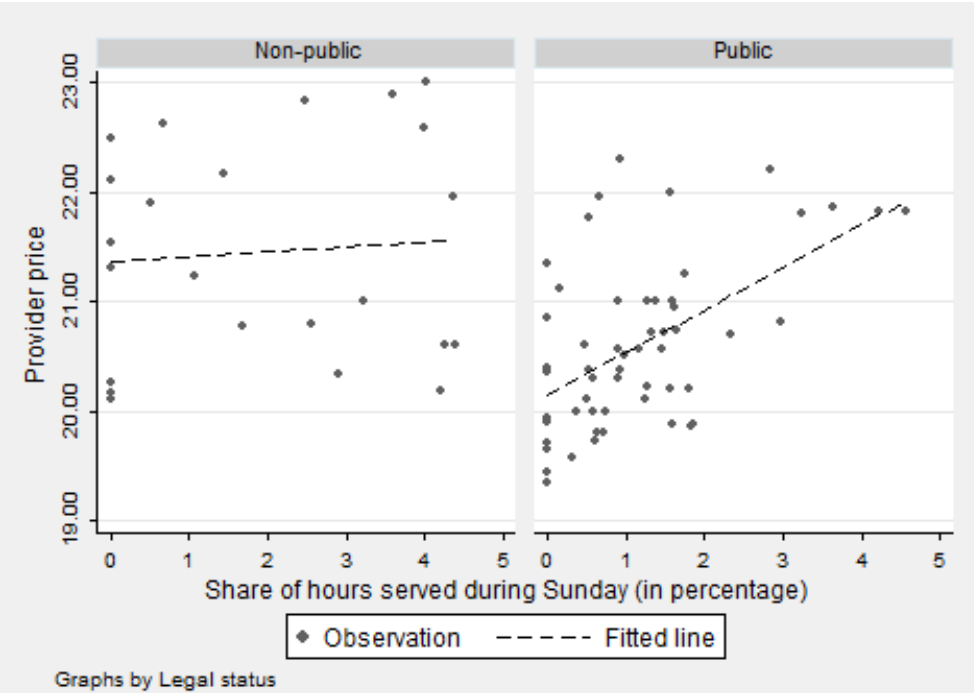

SAMPLE: Authorized providers of the department serving at least one APA beneficiary in October 2012, 2013 or 2014.

Notes: The largest provider, which has $1.80 \%$ of its home care hours provided on Sundays and holidays in 2014, is not included. 


\section{F.2 Correlations between individual characteristics and provider price}

We also investigate the importance of the observable characteristics on the choice of a given level of provider price. Table F.I presents the individual characteristics associated with the choice of a "low-price" authorized provider, defined as a provider charging a price strictly below the average price charged by the authorized providers operating in the beneficiary's municipality (in a given month). We estimate the probability of choosing a "low-price" provider by a Probit on the sub-sample of individuals who live in a municipality where several authorized providers serve APA recipients. Beyond a slight age effect, only the disability level is found to have a significant impact. The least severely disabled are more likely to choose a "low-price" provider, possibly reflecting that they perceive home care as less necessary and are thus ex ante more sensitive to its price. Income is not found to have any impact on this choice, nor is matrimonial status (Fisher tests reject the joint significance of both the set of income quartile dummies and the set of matrimonial status dummies). ${ }^{47}$

[Table F.I to be found on the following page]

\footnotetext{
${ }^{47}$ Although we do not find any evidence that beneficiaries who are able to choose between different authorized providers choose a price level according to their income, it might still be the case that there is systematic correlation between income and provider price in the sample, as about $30 \%$ of beneficiaries are suspected not to be able to choose between different providers (Appendix G.3). When we take our estimation sample and regress the provider price on income and all the socio-demographic variables we include in our estimations as well as year dummies, we find a negative partial correlation between income and provider price. Although it is statistically significant, it is fairly small: a one standard-deviation increase in disposable income is predicted to decrease provider price by 0.01 standard-deviation. This is small enough not to undermine the separate identification of the price and empirical income elasticities.
} 
Table F.I: Individual characteristics associated with the choice of a low provider price

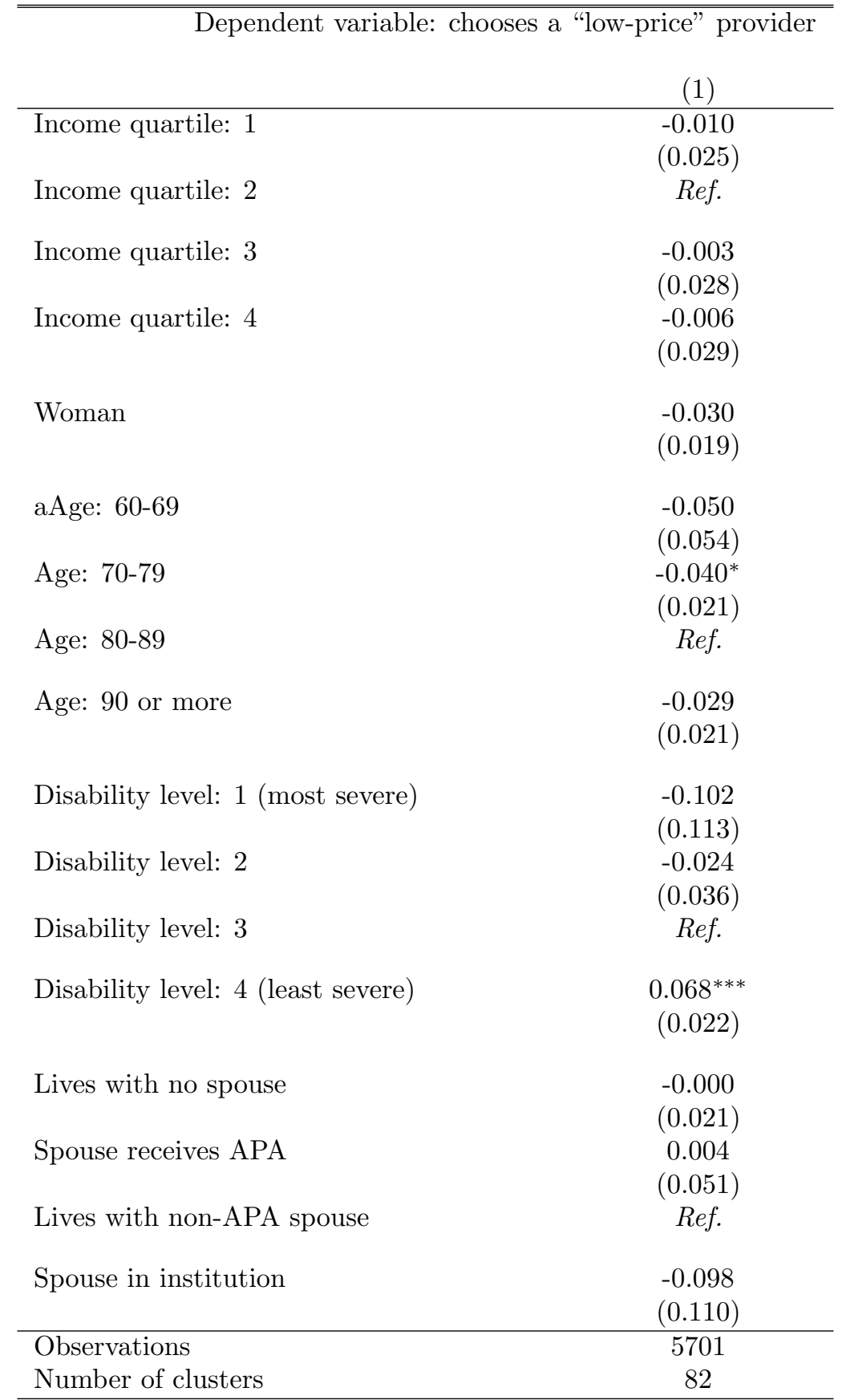

NOTES: Standard errors in parentheses, clustered at the municipality level; ${ }^{*} p<0.10,{ }^{* *} p<0.05,{ }^{* * *} p<0.01$. Estimation of a Probit model by Maximum Likelihood. Average partial effects (APE) are displayed. "Low-price" providers are charging a price below the average price of authorized providers within a given municipality (in one given month: October 2012, 2013 or 2014); the estimation uses the sample of beneficiaries served by only an authorized provider living in a municipality where at least two different prices are offered by authorized providers. Data pooled from October 2012, October 2013 and October 2014. Specifications include year fixed effects. 


\section{G ROBUSTNESS CHECKS}

\section{G.1 Additional results: absolute or relative consump- tion}

In this section, we present the results obtained on the pooled sample and by year, fitting several specifications. Table G.I presents the estimates of the first specification, when the dependent variable is the absolute consumption (Equation (7), Appendix B.1). Tables G.II and Table G.III present the results obtained with the second specification, when the dependent variable is the relative consumption, either assuming the provider price is exogenous (Table G.II) or instrumenting it (Table G.III). In all three tables, Column (1) gives the estimate obtained on the pooled sample, while Columns (2) to (4) display the estimates obtained on October 2012, 2013 or 2014.

Whatever the specification, estimates on 2014 are of a lower precision, essentially because there is one provider less (one provider closed down in 2014). The point estimates are also systematically lower (in absolute value) in 2014 than in the other two years, although the difference from one year to the other is never statistically significant.

When the dependent variable is the absolute consumption, the coefficients associated with the price lie between -0.7 and -1.0: they are higher than those obtained with the relative consumption (between -0.3 and -0.7 with no instrumentation, -0.1 and -0.5 when the IV strategy is implemented). It might be explained by the fact that the care plan volume, which may be a proxy for some unobserved determinants of professional care consumption, is not taken into account in the specification with absolute consumption as the dependent variable.

With the absolute consumption, the income effect within the APA scheme is suggested to be negative. When taking the relative consumption as the dependent variable, and including the care plan volume as a control, point estimates are lower in absolute value (presumably because the omitted variable bias is reduced); the effect of income within the APA scheme is no longer significant. The IV-strategy only little affects point estimates. Except for 2014, we can systematically reject that the price elasticity is zero.

Overall, these results confirm that the price elasticity is significantly different from zero and inferior to one in absolute value. The -0.4 point estimate we finally retain is the one that is the most likely to be unbiased (care plan volume as a control \& IV strategy) and the most precise (pooled data with 
both intra- and inter- individual price variations). Yet we must acknowledge the relatively low precision of our results: the 95\%-level confidence interval derived from our favoured specification indicates a price elasticity between -0.01 and -0.76 .

\section{[Tables G.I and G.II to be found on the following page; \\ Table G.III to be found on page 50]}

Table G.I: Censored regression estimates of demand for home care hours (absolute consumption)

\begin{tabular}{lcccc}
\hline \hline \multicolumn{4}{c}{ Dependent variable: absolute consumption $h^{*}(\log )$} \\
& $(1)$ & $(2)$ & $(3)$ & $(4)$ \\
& $2012-14$ & 2012 & 2013 & 2014 \\
\hline Price $(\log )$ & $-0.793^{* * *}$ & $-0.977^{* * *}$ & $-0.721^{* *}$ & $-0.709^{* *}$ \\
& $(0.248)$ & $(0.260)$ & $(0.297)$ & $(0.290)$ \\
& & & & \\
Disposable income $(\log )$ & $-0.039^{* * *}$ & $-0.033^{* * *}$ & $-0.039^{* * *}$ & $-0.048^{* * *}$ \\
& $(0.010)$ & $(0.012)$ & $(0.015)$ & $(0.019)$ \\
\hline Other controls & Yes & Yes & Yes & Yes \\
\hline Observations & 8190 & 2571 & 2757 & 2862 \\
Censored observations & $36.6 \%$ & $40.4 \%$ & $38.2 \%$ & $40.2 \%$ \\
Number of clusters & 28 & 28 & 28 & 27 \\
\hline
\end{tabular}

NOTES: Standard errors in parentheses, clustered at the provider level; ${ }^{*} p<$ $0.10,{ }^{* *} p<0.05,{ }^{* * *} p<0.01$. Data from October 2012, 2013 and 2014 . Estimation of a Tobit model by Maximum Likelihood. All specifications include as controls socio-demographic variables, dummies for the year the latest plan was decided upon and dummies for the year in which the copayment rate was computed. Column (1) additionally includes year fixed effects. 
Table G.II: Censored regression estimates of demand for home care hours (relative consumption)

\begin{tabular}{lcccc}
\hline \multicolumn{5}{c}{ Dependent variable: relative consumption $h^{*} / \bar{h}(\log )$} \\
& $(1)$ & $(2)$ & $(3)$ & $(4)$ \\
& $2012-14$ & 2012 & 2013 & 2014 \\
\hline Price $(\log )$ & $-0.450^{* *}$ & $-0.670^{* * *}$ & -0.376 & -0.300 \\
& $(0.181)$ & $(0.180)$ & $(0.236)$ & $(0.238)$ \\
& & & & \\
Disposable income $(\log )$ & -0.010 & -0.003 & -0.014 & -0.014 \\
& $(0.008)$ & $(0.009)$ & $(0.009)$ & $(0.016)$ \\
Care plan volume $(\log )$ & $0.040^{*}$ & $0.054^{*}$ & 0.019 & 0.041 \\
& $(0.023)$ & $(0.030)$ & $(0.027)$ & $(0.033)$ \\
\hline Other controls & Yes & Yes & Yes & Yes \\
\hline Observations & 8190 & 2571 & 2757 & 2862 \\
Censored observations & $36.6 \%$ & $40.4 \%$ & $38.2 \%$ & $40.2 \%$ \\
Number of clusters & 28 & 28 & 28 & 27 \\
\hline \hline
\end{tabular}

Notes: Standard errors in parentheses, clustered at the provider level; ${ }^{*} p<0.10,{ }^{* *} p<0.05,{ }^{* * *} p<0.01$. Data from October 2012, 2013 and 2014. Estimation of a Tobit model by Maximum Likelihood. All specifications include as controls socio-demographic variables, dummies for the year the latest plan was decided upon and dummies for the year in which the co-payment rate was computed. Column (1) additionally includes year fixed effects. 
Table G.III: Censored regression estimates of demand for home care hours (relative consumption, IV)

\begin{tabular}{|c|c|c|c|c|}
\hline & $\begin{array}{c}(1) \\
2012-14\end{array}$ & $\begin{array}{c}(2) \\
2012\end{array}$ & $\begin{array}{c}(3) \\
2013\end{array}$ & $\begin{array}{c}(4) \\
2014\end{array}$ \\
\hline Panel A: Second Stage & \multicolumn{4}{|c|}{ Dependent variable: relative consumption $h^{*} / \bar{h}(\log )$} \\
\hline Price (log) & $\begin{array}{c}-0.387^{* *} \\
(0.192)\end{array}$ & $\begin{array}{c}-0.537^{* *} \\
(0.209)\end{array}$ & $\begin{array}{c}-0.460^{* *} \\
(0.214)\end{array}$ & $\begin{array}{c}-0.134 \\
(0.245)\end{array}$ \\
\hline Disposable income (log) & $\begin{array}{l}-0.010 \\
(0.008)\end{array}$ & $\begin{array}{l}-0.003 \\
(0.009)\end{array}$ & $\begin{array}{l}-0.014 \\
(0.008)\end{array}$ & $\begin{array}{c}-0.014 \\
(0.016)\end{array}$ \\
\hline Care plan volume (log) & $\begin{array}{c}0.040^{*} \\
(0.023)\end{array}$ & $\begin{array}{l}0.054^{*} \\
(0.030)\end{array}$ & $\begin{array}{c}0.019 \\
(0.028)\end{array}$ & $\begin{array}{c}0.042 \\
(0.033)\end{array}$ \\
\hline Panel B: First Stage & \multicolumn{4}{|c|}{ Dependent variable: provider price $p(\log )$} \\
\hline Number of municipalities (std.) & $\begin{array}{c}0.049^{* * *} \\
(0.004)\end{array}$ & $\begin{array}{c}0.050^{* * *} \\
(0.004)\end{array}$ & $\begin{array}{c}0.046^{* * *} \\
(0.004)\end{array}$ & $\begin{array}{c}0.050^{* * *} \\
(0.004)\end{array}$ \\
\hline Other controls & Yes & Yes & Yes & Yes \\
\hline Observations & 8190 & 2571 & 2757 & 2862 \\
\hline Censored observations & $36.6 \%$ & $40.4 \%$ & $38.2 \%$ & $40.2 \%$ \\
\hline Number of clusters & 28 & 28 & 28 & 27 \\
\hline \multicolumn{5}{|c|}{$\begin{array}{l}\text { NOTES: Standard errors in parentheses, clustered at the provider level; }{ }^{*} p<0.10,{ }^{* *} p< \\
0.05,{ }^{* * *} p<0.01 \text {. Data from October } 2012,2013 \text { and } 2014 \text {. Estimation of an IV-Tobit } \\
\text { model by Maximum Likelihood. Price is instrumented by the number of municipalities } \\
\text { served by the provider. In the first stage (Panel B), the log-provider price is regressed } \\
\text { on the standardized number of municipalities served by the provider. All specifications, } \\
\text { for both Panel A and Panel B, include as controls socio-demographic variables, dummies } \\
\text { for the year the latest plan was decided upon and dummies for the year in which the } \\
\text { co-payment rate was computed. Column (1) additionally includes year fixed effects. }\end{array}$} \\
\hline
\end{tabular}




\section{G.2 Clustering and Bootstrap inference}

\section{Level of clustering}

In the paper, we denote $\tilde{\epsilon}_{i t}$ the error term in our favoured specification (Equation (5)). As we cluster at the provider level $j$, we actually implicitly assume the following structure for the error term $\tilde{\epsilon}$ :

$$
\tilde{\epsilon}_{i j t}=\tilde{\xi}_{i}+\tilde{\nu}_{j}+\tilde{\zeta}_{i j t}
$$

with $\tilde{\xi}_{i}$ capturing the unobserved individual heterogeneity, and $\tilde{\nu}_{j}$ the provider level time-invariant unobserved heterogeneity. For two individuals $i$ and $i^{\prime}$ that are served by the same provider $j$ (assume for the sake of simplicity that $t$ is not varying $), \operatorname{corr}\left(\tilde{\epsilon}_{i j t}, \tilde{\epsilon}_{i^{\prime} j t}\right) \neq 0$ as long as there are unobserved shocks taking place at the provider level.

For a given individual observed at $t$ and $t^{\prime}$, error terms will be necessarily correlated if there is some individual time-invariant unobserved heterogeneity. ${ }^{48}$ As standard with panel data, we would need to cluster at the individual level. Yet, as almost all APA beneficiaries keep the same provider $j$ over time, the latter way of clustering (at the individual level) is essentially nested in the former clustering option (at the provider level). We believe that within-individual correlation of errors is more important than within-provider shock correlation; we nonetheless choose to cluster at the most aggregate level. In our specific setting, in which our main explanatory variable varies at the provider-year level, clustering at the provider level is of due caution as the provider price does not change within one cluster cross-sectionally (Moulton, 1990; Cameron and Miller, 2015).

\section{Inference with few clusters}

With clustered standard errors, inference relies on asymptotic properties that kick in as the number of clusters tends to infinity. The "few-cluster issue" was documented notably by Cameron et al. (2008): in an OLS setting, Wald hypothesis tests based on the standard cluster-robust estimate of the variance matrix tend to over-reject the null. Rejection rates increase when clusters are of unequal sizes (Imbens and Kolesár, 2015).

In our department, there are relatively few authorized providers (28 in 2012

\footnotetext{
${ }^{48}$ Note that we are not able to include individual fixed-effects in the type 1-Tobit model, as there is no parametric solution to the incidental parameter problem (Lancaster, 2000).
} 
and 2013, 27 in 2014 as one provider closed down). ${ }^{49}$ and there is one very large authorized provider (Figure G.1). This service is a local branch of a long-standing nationwide non-profit home care service; it serves $37 \%$ of the APA beneficiaries in our sample. With only 28 clusters, including one being considerably larger than the others, we face the risk that standard clusterrobust inference is biased.

Figure G.1: Distribution of the size of authorized providers (October 2014)

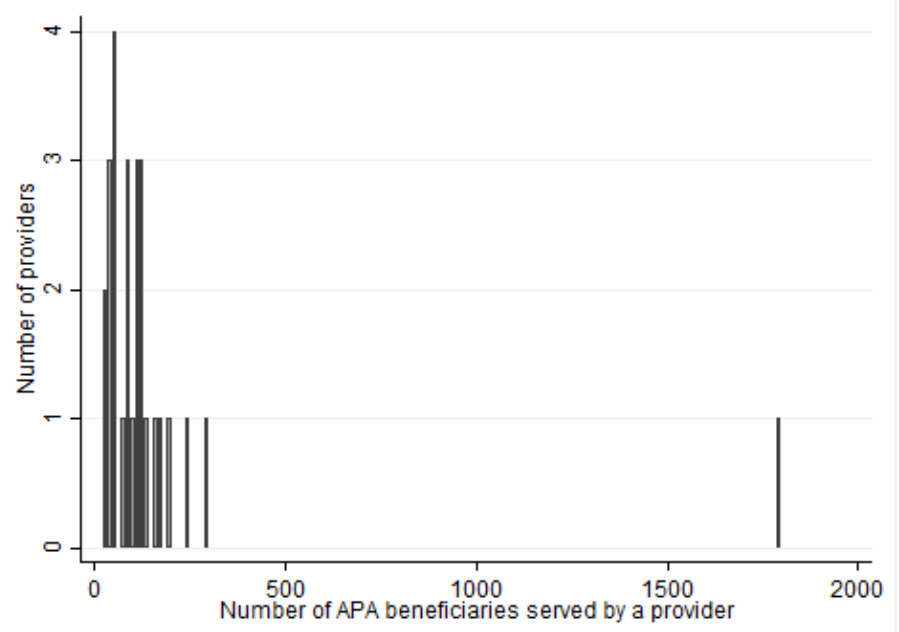

Notes: Size of a provider is measured by the number of APA beneficiaries it serves. Data from October 2014, 27 authorized providers (one authorized provider closed down in 2014).

In order to assess the robustness of the inference on the estimates presented in the paper, we use a bootstrap procedure. By bootstrapping the Wald tstatistic associated with the price elasticity estimate $\hat{\tilde{\beta}}_{1}$, we may improve smallsample inference by attaining asymptotic refinement (Cameron and Miller, 2015).

We start by estimating our equation on the original sample (by Tobit or IV-Tobit)..$^{50}$ We retrieve the point estimate of the price elasticity, $\hat{\beta}_{1}$ and its standard error, se $\left(\hat{\tilde{\beta}}_{1}\right)$, and we compute the original sample Wald t-statistic $t=\hat{\tilde{\beta}}_{1} / \operatorname{se}\left(\hat{\tilde{\beta}}_{1}\right)$. We then implement a percentile pair cluster bootstrap, by repeating 1,000 times the following steps:

\footnotetext{
${ }^{49}$ This is not a feature specific to our department though (LEDa-LEGOS and CES, 2012).

${ }^{50}$ Here, as well as in the subsequent bootstrap replications, we do not use Stata's ivtobit command, through which standard errors are derived using the observed information matrix (oim). Instead, we first regress the (log) provider price on the instrument and the other exogenous controls (clustering at the provider level) and derive a prediction of the log of the provider price. We run the second step by regressing the (log) relative consumption on the predicted log-provider price and the other controls, again clustering at the provider level. It gives the inputs we use in the bootstrap procedure.
} 
1. We form 28 "pair" clusters of observations by re-sampling with replacement 28 times from the original clustered sample.

2. For each bootstrap sample $b=1, \ldots, 1000$, we estimate $\hat{\tilde{\beta}}_{1}^{b}$ (by Tobit or IV-Tobit), and the associated cluster-robust standard error $\operatorname{se}\left(\hat{\tilde{\beta}}_{1}^{b}\right)$.

3. For each bootstrap sample $b$, we compute the Wald t-statistic centered in $\hat{\tilde{\beta}}_{1}$ :

$$
t_{b}=\frac{\hat{\tilde{\beta}}_{1}^{b}-\hat{\tilde{\beta}}_{1}}{\operatorname{se}\left(\hat{\tilde{\beta}}_{1}^{b}\right)}, \quad b=1, \ldots, 1000
$$

We then use the empirical distribution of the bootstrap t-statistics $t_{b}$ to derive the critical values to be used in lieu of the critical values derived from a standard normal or $T$ distribution. We compare the t-statistic associated with the price elasticity coefficient obtained in the observed sample to the symmetrical critical values derived from the bootstrapped t-statistic distribution. The percentile-t p-value for the symmetric two-sided Wald test of H0: " $\tilde{\beta}_{1}=0$ " is computed as the proportion of times the absolute value of the boostrapped t-statistic is greater than the absolute value of the observed sample t-statistic; that is to say, the proportion of times that $\left|t_{b}\right|>|t|, \quad b=1, \ldots, 1000$

Issues may arise when using pair cluster resampling with dummy control variables: some of the bootstrap samples may have little or even no variation in the control variables. The computation of $t_{b}$ in those samples is not possible; using the bootstrap t-statistics that were actually computed is not an option either, as completed replications cannot be assumed to be random. ${ }^{51}$ In order to avoid failure to complete the target number of cluster bootstrap replications, we drop from our original sample the 8 individuals whose co-payment rate was last reassessed prior to $2011 .^{52}$

Table G.IV displays the price elasticity estimates and compares standard inference with bootstrap inference. Columns (1) to (3) display the estimates obtained using a Tobit model to estimate our specification with relative consumption, while Columns (4) to (6) are derived from an IV-Tobit estimation. Columns (1) and (3) display the original consumer price elasticity estimates obtained by either Tobit or IV-Tobit estimations, while Columns (2) and (5) display the same estimates obtained on the sample on which the pair cluster

\footnotetext{
${ }^{51}$ Wild cluster bootstrap has been documented as leading to more robust inference in the case of few clusters, as well as helping in the case that right-hand side dummy variables induce incomplete replications (Cameron and Miller, 2015). To our knowledge though, wild cluster bootstrap has not been extended to nonlinear models.

${ }^{52}$ Our specifications with absolute and relative consumptions include a dummy for the year in which the co-payment rate was assessed, as justified in Appendix B.1.
} 
bootstrap can be completed. Comparing (1) and (2) first, then (4) and (5), we see that dropping the 8 aforementioned individuals has virtually no effect on the point estimate.

\section{[Table G.IV to be found on the following page]}

Table G.IV: Bootstrap inference

\begin{tabular}{|c|c|c|c|c|c|c|}
\hline & \multicolumn{6}{|c|}{ Dependent variable: relative consumption $h^{*} / \bar{h}(\log )$} \\
\hline & \multicolumn{3}{|c|}{ - — Tobit ——— } & \multicolumn{3}{|c|}{$-\_$IV-Tobit ——— } \\
\hline Price $(\log )$ & $-0.450^{* *}$ & $-0.451^{* *}$ & $-0.451^{* *}$ & $-0.387^{* *}$ & $-0.388^{* *}$ & $-0.386^{* *}$ \\
\hline$(\mathrm{se})$ & $(0.181)$ & $(0.180)$ & - & $(0.192)$ & $(0.192)$ & - \\
\hline p-value & 0.013 & 0.012 & 0.018 & 0.044 & 0.044 & 0.014 \\
\hline Disposable income (log) & -0.010 & -0.010 & -0.010 & -0.010 & -0.010 & -0.010 \\
\hline$(\mathrm{se})$ & $(0.007)$ & $(0.007)$ & - & $(0.007)$ & $(0.007)$ & - \\
\hline p-value & 0.184 & 0.184 & 0.163 & 0.186 & 0.186 & 0.165 \\
\hline Other controls & Yes & Yes & Yes & Yes & Yes & Yes \\
\hline Sample & All & $\begin{array}{r}\text { co-payme } \\
\text { no earlie }\end{array}$ & $\begin{array}{l}\text { reassessed } \\
\text { han } 2011\end{array}$ & All & $\begin{array}{r}\text { co-payme } \\
\text { no earlie }\end{array}$ & $\begin{array}{l}\text { reassessed } \\
\text { than } 2011\end{array}$ \\
\hline Observations & 8190 & 8182 & 8182 & 8190 & 8182 & 8182 \\
\hline Censored observations & $39.6 \%$ & $39.6 \%$ & $39.6 \%$ & $39.6 \%$ & $39.6 \%$ & $39.6 \%$ \\
\hline Inference & Default & Default & Bootstrap & Default & Default & Bootstrap \\
\hline Number of clusters & 28 & 28 & 28 & 28 & 28 & 28 \\
\hline \multirow{2}{*}{\multicolumn{7}{|c|}{$\begin{array}{l}\text { NOTES: Standard errors in parentheses, the provider level; }{ }^{*} p<0.10,{ }^{* *} p<0.05,{ }^{* * *} p<0.01 \\
\text { Data pooled from October } 2012,2013 \text { and } 2014 \text {. Estimation of a Tobit or IV-Tobit model by } \\
\text { Maximum Likelihood (Stata commands tobit for Columns }(1) \text { to }(3) \text {, and ivtobit for Columns }(4) \\
\text { and }(5)) \text {. In Columns }(3) \text { and }(6) \text {, inference is obtained using a bootstrap procedure. Difference in } \\
\text { the point estimates between Columns }(5) \text { and }(6) \text { is due to the fact that in Column }(6) \text { we implement } \\
\text { manually the IV strategy in two separate steps, rather than using the ivtobit command, to make } \\
\text { the Bootstrap procedure consistent. } \\
\text { SAMPLES: In Columns }(2),(3),(5) \text { and }(6) \text {, individuals whose co-payment rate was reassessed prior } \\
\text { to } 2011 \text { are not included in the sample ( } 8 \text { individuals). }\end{array}$}} \\
\hline & & & & & & \\
\hline \multicolumn{7}{|c|}{$\begin{array}{l}\text { BOOTSTRAP INFERENCE: We implement a pair cluster percentile bootstrap of the t-statistics }(1,000 \\
\text { replications). The percentile-t p-value for the symmetric two-sided Wald test of H0: } \tilde{\beta}_{1}=0 \text {, is } \\
\text { computed as the proportion of times the absolute value of the boostrap t-statistic is greater than } \\
\text { the absolute value of the observed sample t-statistic. }\end{array}$} \\
\hline
\end{tabular}

The Tobit estimation of the specification with the relative consumption produces a t-stat equal to -2.50 . The $25^{\text {th }}$ lowest value of the bootstrap tstatistics is -1.87 , while its $975^{\text {th }}$ is equal to 1.90 . Using a symmetric Wald test, we find that the absolute value of the original t-stat is larger than $\left|t_{b}\right|$ a little less than $99 \%$ of times (p-value of 0.018, Column (3) of Table G.IV). Bootstrap inference thus indicates that we can reject the hypothesis that the price elasticity is zero at the $5 \%$ level.

Similarly, the IV-Tobit estimation of the specification with relative consumption produces a t-stat equal to -1.93 . The $25^{\text {th }}$ lowest value of the bootstrap t-statistics is -1.73 , while its $975^{\text {th }}$ is equal to 1.38 . Using a symmetric 
Wald test, we reject the hypothesis that the relative consumption of home care is price inelastic, again at the $5 \%$ level.

Figures G.2 and G.3 display the empirical distribution of the bootstrap t-statistics obtained following either the Tobit or the IV-Tobit estimation of the consumer price elasticity. We display a normal distribution with mean and variance equal to the mean and variance of the empirical distribution of the bootstrap t-statistics, and the normal distribution with mean 0 and variance 1 as a benchmark. Despite the sample containing one very large cluster, we observe a quite smooth distribution of t-statistics in both Figures. All replications are complete and the tails of the distribution do not seem excessively fat, making us confident in the quality of our bootstrap and in the statistical power of the deriving Wald test on the price elasticity estimate.

Figure G.2: Percentile-t bootstrap quality: distribution of bootstrap t-statistics (Tobit estimation)

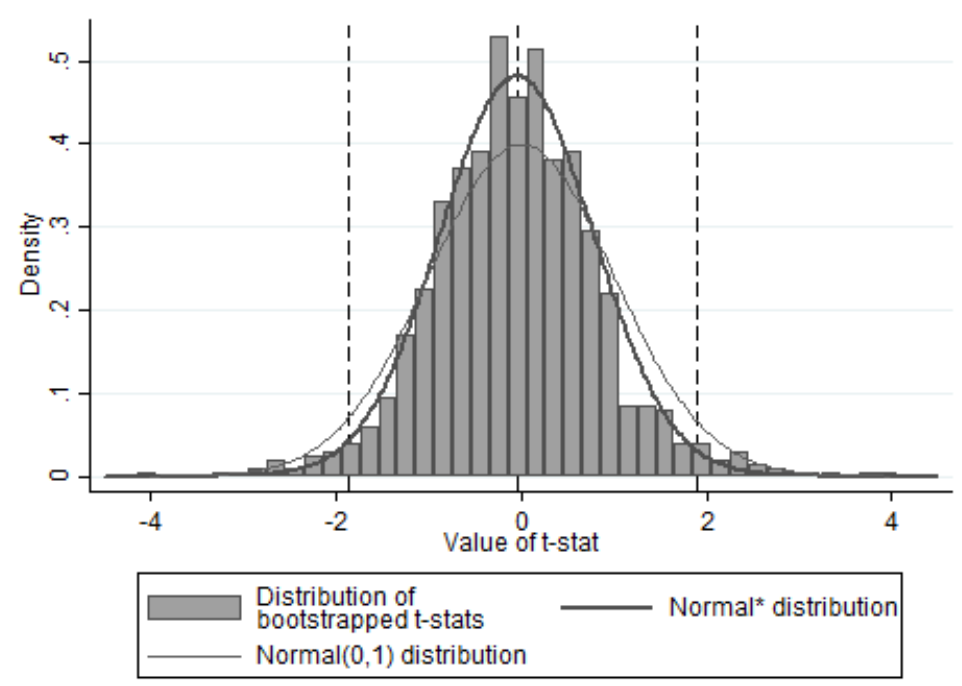

Notes: t-stats from percentile bootstrap-t (1,000 replications). Output from Tobit estimation on relative consumption (Column (3) of Table G.IV) on sample of 8,182 individuals. ${ }^{*}$ The first normal distribution displayed has a mean and variance equal to the mean and variance of the distribution of bootstrap t-stats. Dashed vertical lines represent the $25^{\text {th }}$ and $975^{\text {th }}$ ordered elements and the mean of the bootstrap t-stat distribution. 
Figure G.3: Percentile-t bootstrap quality: distribution of bootstrap t-statistics (IV-Tobit estimation)

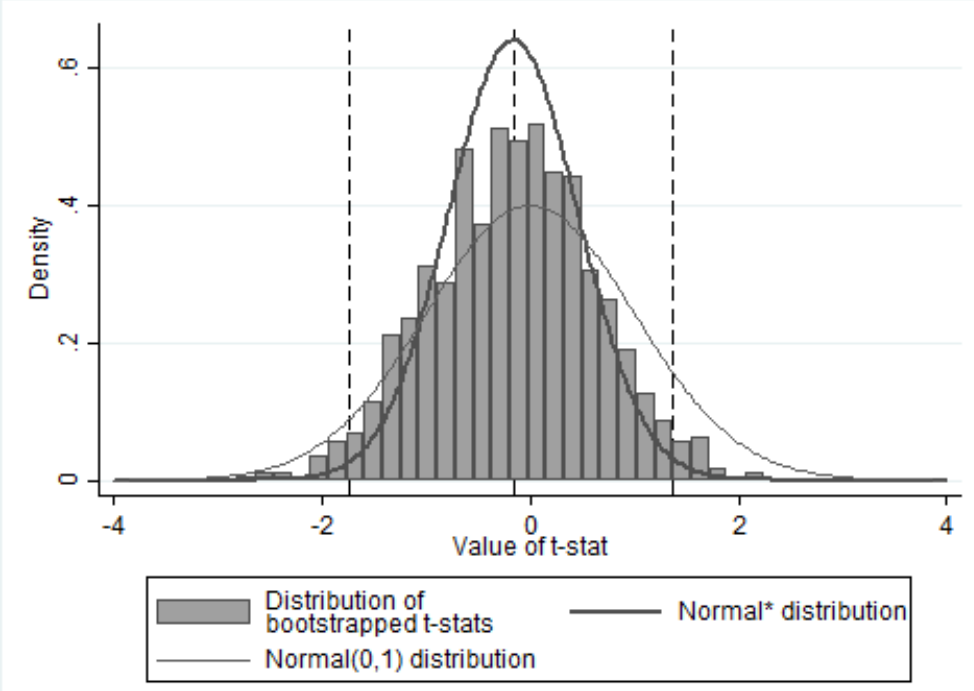

Notes: t-stats from percentile bootstrap-t (1,000 replications). Output from manual IV-Tobit estimation on relative consumption (Column (6) of Table G.IV) on sample of 8,182 individuals. ${ }^{*}$ The first normal distribution displayed has a mean and variance equal to the mean and variance of the distribution of bootstrap t-stats. Dashed vertical lines represent the $25^{\text {th }}$ and $975^{\text {th }}$ ordered elements and the mean of the bootstrap t-stat distribution. 


\section{G.3 Alternative identification strategy: using single- provider areas}

\section{Single-provider and multiple-provider areas}

According to their geographical location in the department, beneficiaries may not be systematically able to choose between several providers of the department. We divide our sample into two sub-populations (Figure G.4): on the one side, beneficiaries living in a municipality where a single provider is found to operate, or single-provider area (denoted "SPA"; areas in plain color). On the other side, individuals living in a municipality where two or more authorized providers have customers, or multiple-provider area (denoted "non-SPA"; dotted areas). ${ }^{53}$

Figure G.4: Distribution of providers in the department - Schematic representation

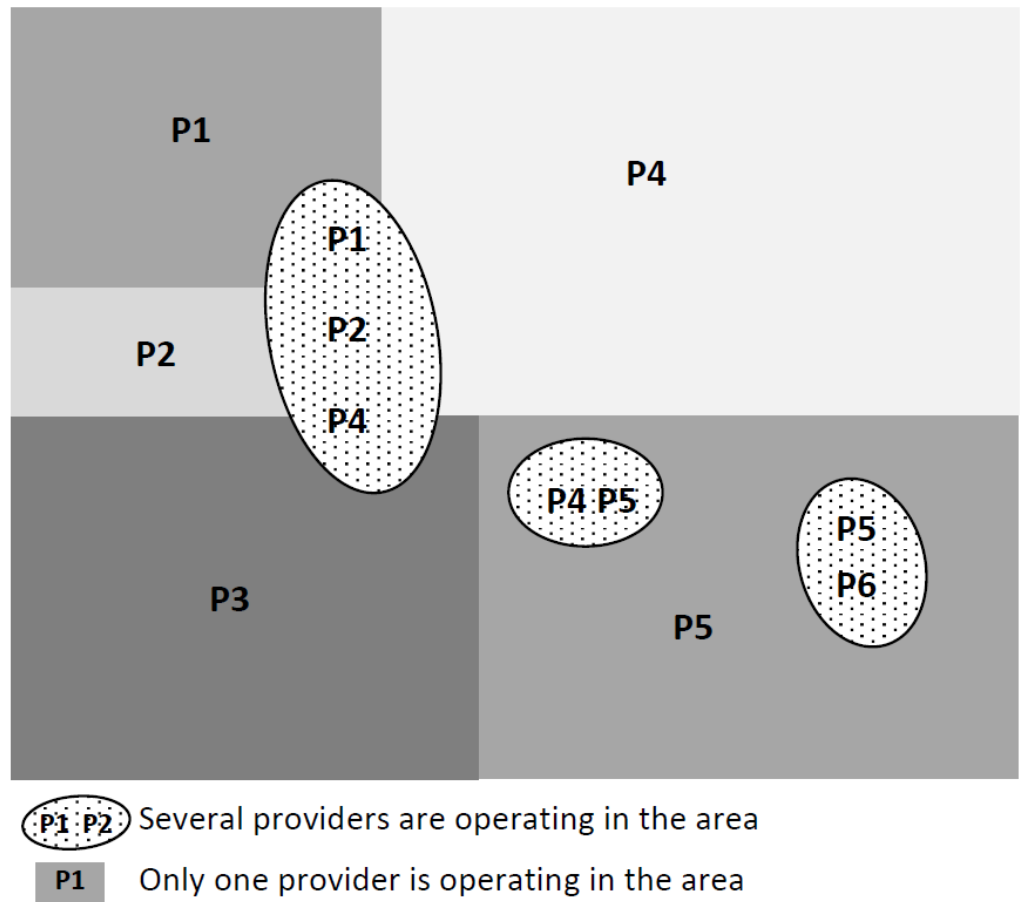

Notes: We provide only a schematic representation to preserve the anonymity of the department. Different shades of plain grey indicate different areas served by a unique authorized service (single-provider areas, or SPA), each being served by a different provider with a given price level. The dotted areas correspond to multiple-provider (non-SPA) municipalities.

As displayed in Table G.V, 79\% of the municipalities represented in our sample belong to an SPA; 35\% of beneficiaries included in the estimation sam-

\footnotetext{
${ }^{53}$ To identify the two types of areas, we use the full population of APA beneficiaries in the department, not only the APA beneficiaries of our estimation sample.
} 
ple live in this type of areas. The remaining beneficiaries live in a municipality where two or more authorized providers have customers. This partition interestingly reflects the spatial concentration of the APA population: $65 \%$ of the beneficiaries in our sample live in $21 \%$ of the department municipalities. Consistently, non-SPA municipalities are more often urban centers than SPA municipalities.

Table G.V: Single-provider areas and multiple-provider areas (October 2014)

\begin{tabular}{|l|c|c|c|c|c|}
\hline \hline \multirow{2}{*}{} & \multicolumn{2}{|c|}{ Municipalities } & \multicolumn{2}{c|}{ Beneficiaries } & Average \\
& Number & Frequencies & Number & Frequencies & \\
\hline SPA & 220 & $78.9 \%$ & 995 & $34.8 \%$ & $€ 22.7$ \\
Non-SPA & 59 & $21.1 \%$ & 1,867 & $65.2 \%$ & $€ 22.0$ \\
& 279 & $100 \%$ & 2,862 & $100 \%$ & - \\
Total & & & & \\
\hline
\end{tabular}

NOTES: Estimation sample from October 2014. Average provider price per type of area is not weighted by the number of customers of the providers.

The spatial distribution of professional care provision is consistent with the fact that transportation costs are an important factor in the provision decision of home care services (cf. Section 4.4 of the paper). Providing services all over the department would be costly for a relatively small service. Typically, municipalities where only one provider is found to operate are served by nonprofit home care services. In urban centers, the supply proposed by non-profit services may be complemented with municipal home care services, or even, in the largest municipalities, with one of the few for-profit authorized services found in the department (cf. Appendix E.2).

Table G.VI presents the descriptive statistics computed on the two subsamples of APA beneficiaries, depending on the type of area in which they live. The two sub-samples are similar in terms of their socio-demographic characteristics albeit non-SPA residents are richer on average. This is consistent with the fact that non-SPA residents tend to locate in urban centers. The under-consumption rate is higher among non-SPA beneficiaries, but the average number of hours effectively subsidized is similar in both types of areas. This goes against the concern that SPA beneficiaries may experience rationing in the provision of professional care. Although subsidized consumption relative to the care plan volume is slightly higher for SPA beneficiaries on average ( $86 \%$ versus $84 \%$ ), the overall distribution of relative consumption is fairly similar in the two sub-samples. Overall, except for the income level, the two populations little differ in terms of outcome and explaining variables. 
Table G.VI: Descriptive statistics on the two sub-samples (SPA/non-SPA, October 2014)

\begin{tabular}{|c|c|c|c|}
\hline Variable & $\begin{array}{c}S P A \\
{[1]}\end{array}$ & $\begin{array}{c}\text { Non-SPA } \\
{[2]}\end{array}$ & $\begin{array}{c}\text { Difference } \\
\text { (p-value) } \\
{[1]-[2]}\end{array}$ \\
\hline Care plan volume [a] & 20.1 & 20.8 & 0.06 \\
\hline Care plan monetary value $[\mathrm{b}]$ & $€ 456.8$ & $€ 454.8$ & 0.83 \\
\hline Hours effectively subsidized [c] & 17.5 & 17.8 & 0.38 \\
\hline Amount of effective subsidies [d] & $€ 311.7$ & $€ 294.9$ & 0.03 \\
\hline$[\mathrm{c}]$ inferior to $[\mathrm{a}]$ & $57.2 \%$ & $61.2 \%$ & 0.03 \\
\hline Individualized income & $€ 1,272$ & $€ 1,339$ & 0.00 \\
\hline co-payment rate & $21.9 \%$ & $24.6 \%$ & 0.00 \\
\hline Provider price & $€ 22.8$ & $€ 21.8$ & 0.00 \\
\hline Hourly out-of-pocket price & $€ 5.0$ & $€ 5.4$ & 0.01 \\
\hline $\begin{array}{l}\text { Total OOP payments } \\
\text { on subsidized hours }\end{array}$ & $€ 86.0$ & $€ 94.2$ & 0.03 \\
\hline Age & 84.4 & 84.0 & 0.18 \\
\hline Women & $72.5 \%$ & $74.7 \%$ & 0.18 \\
\hline Disability level 1 (most severe) & $1.5 \%$ & $1.0 \%$ & \multirow{5}{*}{0.54} \\
\hline Disability level 2 & $12.2 \%$ & $12.6 \%$ & \\
\hline Disability level 3 & $20.7 \%$ & $19.1 \%$ & \\
\hline Disability level 4 (least severe) & $65.6 \%$ & $67.3 \%$ & \\
\hline & $100 \%$ & $100 \%$ & \\
\hline Living with a spouse & $34.7 \%$ & $33.3 \%$ & \multirow{4}{*}{0.81} \\
\hline Living alone & $64.7 \%$ & $66.1 \%$ & \\
\hline \multirow[t]{2}{*}{ Spouse in institution } & $0.6 \%$ & $0.6 \%$ & \\
\hline & $100 \%$ & $100 \%$ & \\
\hline Number of individuals & 995 & 1867 & - \\
\hline Number of households & 965 & 1820 & - \\
\hline
\end{tabular}

NotES: Estimation sample from October 2014. Descriptive statistics are computed on the sub-sample of APA beneficiaries living in single-provider municipalities (SPA) in Column (1) and those living in multiple-provider municipalities (non-SPA) in Column (2). Compared to Table G.V, average provider price in each sub-sample is weighted by the number of beneficiaries in the sample.

TESTS: Last column presents the p-values associated with the tests of difference between SPA and non-SPA beneficiaries. Test performed is a Student (resp. a Pearson $\chi^{2}$ ) for binary or continuous (resp. categorical) variables.

\section{Price elasticity estimates using SPA and non-SPA beneficiaries}

Arguably, SPA beneficiaries have limited choice if they resort to an authorized provider. As a consequence, they are not able to choose their price $p_{i}^{j}$. Note that home care price endogeneity due to residential mobility is suggested to be negligible: the overall residential mobility of the elderly is very low (Laferrère, 2008) and when moves occur, they are mainly explained by family motives or the need for adapted residences. Price endogeneity should thus be limited in the SPA sub-sample; on the contrary, we suspect it may arise in the non-SPA sample. Comparing the price elasticity estimates obtained on the two sub-samples may thus provide a test of price endogeneity in the 
estimation sample.

The estimation is run using the specification with the relative consumption, the outcome being $h_{i t}^{*} / \bar{h}_{i t}$. Results are displayed in Table G.VII. ${ }^{54}$ As presented in the paper, the price elasticity is of -0.45 when estimated on the whole sample, significantly different from zero at the $5 \%$ level. Restricting the sample to individuals who are assumed to have no provider choice, the point estimate slightly changes to -0.52. Because of reduced sample size and price variations, precision is lower but the estimate is still significantly different from zero at the $10 \%$ level.

The point estimate is higher when we run the estimation on the subpopulation of individuals who can choose between different providers, with a point value of -0.63 . The difference between the two sub-sample estimates might potentially be explained by both an omitted variable bias affecting the choice of the provider price and some differences in the characteristics of the individuals of the two samples. However, the difference is not statistically significant even at the $10 \%$ level. Overall, this alternative estimation strategy (relying on SPA beneficiaries only) confirms our main results: the consumption of home care by the disabled elderly is price-elastic, with a point estimate inferior to one in absolute value and a magnitude seemingly around -0.5 or -0.4 .

\footnotetext{
${ }^{54}$ We only display the price and income coefficients as the effects of controls are similar to the estimates obtained with the full estimation sample (displayed in Table II of the paper).
} 
Table G.VII: Censored regression estimates of demand for home care hours (SPA/nonSPA)

\begin{tabular}{|c|c|c|c|}
\hline \multicolumn{4}{|c|}{ Dependent variable: relative consumption $h^{*} / h(\log )$} \\
\hline Sample: & $\begin{array}{l}\text { All } \\
(1)\end{array}$ & $\begin{array}{c}S P A \\
(2)\end{array}$ & $\begin{array}{c}\text { Non-SPA } \\
(3)\end{array}$ \\
\hline Price $(\log )$ & $\begin{array}{c}-0.450^{* *} \\
(0.181)\end{array}$ & $\begin{array}{l}-0.522^{*} \\
(0.305)\end{array}$ & $\begin{array}{c}-0.626^{* *} \\
(0.258)\end{array}$ \\
\hline Disposable income (log) & $\begin{array}{l}-0.010 \\
(0.008)\end{array}$ & $\begin{array}{c}0.001 \\
(0.010)\end{array}$ & $\begin{array}{l}-0.013 \\
(0.009)\end{array}$ \\
\hline Care plan volume (log) & $\begin{array}{l}0.040^{*} \\
(0.023)\end{array}$ & $\begin{array}{c}0.039^{* * *} \\
(0.014)\end{array}$ & $\begin{array}{l}0.049^{*} \\
(0.029)\end{array}$ \\
\hline Other controls & Yes & Yes & Yes \\
\hline Observations & 8190 & 2489 & 5701 \\
\hline Censored observations & $39.6 \%$ & $40.7 \%$ & $39.1 \%$ \\
\hline Number of clusters & 28 & 18 & 28 \\
\hline$A I C$ & 11454 & 3277.318 & 8144 \\
\hline$B I C$ & 11643 & 3376.252 & 8324 \\
\hline
\end{tabular}

NOTES: Standard errors in parentheses, clustered at the provider level; ${ }^{*} p<0.10,{ }^{* *} p<0.05,{ }^{* * *} p<0.01$. Pooled data from October 2012, 2013, 2014. Estimation of a Tobit model by Maximum Likelihood. All specifications include as controls sociodemographic variables, dummies for the year the latest plan was decided upon, dummies for the year in which the co-payment rate was computed and year fixed effects. SPA stands for "single-provider area" beneficiaries, non-SPA for "multiple-provider area" beneficiaries. 
This alternative identification strategy has several drawbacks. First, focusing on SPA beneficiaries induces additional intra-departmental selection. We find the non-SPA to be richer than SPA beneficiaries. If richer individuals are more price-elastic, as suggested by Table III in the main text, the price elasticity obtained on the SPA sub-sample would then be a lower bound (in absolute value) for the average price elasticity of our estimation sample. But we may additionally suspect that the two sub-samples differ in terms of unobservable determinants of professional care consumption. Using the specification with relative consumption, we tested the effect of including a dummy equal to one for SPA beneficiaries (Table G.VIII): living in a SPA is found to positively affect home care relative consumption, ceteris paribus. The inclusion of the SPA dummy affects the price elasticity estimate (although not statistically significantly). This might suggest that SPA beneficiaries behave differently than non-SPA in terms of care consumption decisions.

\section{[Table G.VIII to be found on the following page]}

One might fear that authorized providers operating as monopolies may set their price in accordance with the price elasticity of demand. In SPA municipalities, provider prices could be higher where the price sensitivity of APA beneficiaries is lower, inducing a potential downward bias (in absolute value) in our point elasticity estimate. Given that the authorized providers operating in an SPA are systematically non-profit structures and that they are priced by the Departmental Council, there is limited scope for consumer surplus extraction by monopolist providers.

A more serious issue a priori is that SPA and non-SPA sub-samples are constructed using the available information of our sample. We construct the non-SPA sample by observing the municipalities in which there are beneficiaries served by at least two different authorized providers. ${ }^{55}$ It might be the case, especially in very small municipalities, that there are few beneficiaries living in a municipalities and they happen to all choose the same provider. In this case, we will infer that there is only one provider operating; we do not have any other way to infer from the data whether the individuals were able to choose between different providers. Although such cases are scarce, ${ }^{56}$ we should remain cautious when interpreting the price elasticity estimated on the SPA sample.

\footnotetext{
${ }^{55}$ We do not have direct information on the supply and geographical coverage by the different providers.

${ }^{56} 8 \%$ municipalities turn out to have a unique APA beneficiary, hosting $1 \%$ of the department's beneficiaries. More largely, beneficiaries living in municipalities with 5 or less APA recipients represent around $10 \%$ of total beneficiaries.
} 
Finally, when focusing on SPA beneficiaries, we loose 10 clusters (corresponding to authorized providers who are only found to operate jointly with other providers in the municipalities where they are present). This may undermine the validity of inference in the SPA sub-sample.

Table G.VIII: Censored regression estimates of demand for home care hours, controlling for the type of area of residence

Dependent variable: relative consumption $h^{*} / h(\log )$

\begin{tabular}{lcc} 
& $(1)$ & $(2)$ \\
\hline Price $(\log )$ & $-0.450^{* *}$ & $-0.613^{* * *}$ \\
& $(0.181)$ & $(0.202)$ \\
Disposable income $(\log )$ & -0.010 & -0.008 \\
& $(0.008)$ & $(0.007)$ \\
Lives in a SPA & & $0.064^{* * *}$ \\
& & $(0.023)$ \\
\hline Other controls & Yes & Yes \\
\hline Observations & 8190 & 8190 \\
Censored observations & $36.9 \%$ & $36.9 \%$ \\
Number of clusters & 28 & 28 \\
AIC & 11454 & 11431 \\
$B I C$ & 11644 & 11621 \\
\hline
\end{tabular}

NoTES: Standard errors in parentheses, clustered at the provider level; ${ }^{*} p<0.10,{ }^{* *} p<0.05,{ }^{* * *} p<0.01$. Pooled data from October 2012, 2013 and 2014. Estimation of a Tobit model by Maximum Likelihood. Specifications include as controls sociodemographic variables, dummies for the year the latest plan was decided upon, dummies for the year in which the co-payment rate was computed and year fixed effects. SPA stands for "single-provider area", non-SPA for "multiple-provider area" beneficiaries. 


\section{G.4 Additional results: sensitivity to the inclusion of care received on weekends}

As we do not directly observe the informal care received by the individuals, we include as a control in our estimation the formal home care the individual possibly receives during the weekend and public holidays (Table G.IX).

As in our baseline estimations, the latent dependent variable is the number of hours consumed between Monday and Saturday, except for public holidays, divided by the care plan volume open for business days. Consistently, the care plan volume taken into account to compute relative consumption only includes the hours that were prescribed to be consumed over the week. APA beneficiaries may also be entitled to subsidies for a few hours of care to be received during weekends and public holidays, which are set separately in the personalized care plan. Although weekend hours are charged the same price, they are not fungible with week hours. Only $7.5 \%$ of our estimation sample has weekend hours included in her personalized care plan, for a median volume of about 5 hours a month. ${ }^{57}$ We did not include the home care hours received on weekends as a control in our baseline specifications because of a simultaneity concern.

We hypothesize that, for given disability and socio-demographic characteristics, individuals not receiving professional home care over the weekend are more likely to receive assistance from their relatives. We find that receiving formal care during the weekend is associated with more hours consumed during working days; reassuringly though, it does not significantly affect the price elasticity estimate.

[Table G.IX to be found on the following page]

\footnotetext{
${ }^{57}$ As beneficiaries with weekend care plan volume tend to be more severely disabled, their week care plan volume, $\bar{h}_{i t}$, is on average higher than the week care plan volume of the rest of beneficiaries. Among these beneficiaries, APA hours prescribed on weekends amount only to $15 \%$ of the week care plan volume on average.
} 


\section{G.5 Robustness check: estimation by a truncated re- gression model}

As a further robustness check, we estimate the price sensitivity of the demand for home care using a truncated regression model. We make as if we did not observe all individuals who consume beyond their care plan volume.

A first estimation attempt based on our preferred specification (Equation (9)) was made. Unfortunately, the maximum likelihood is found to have discontinuous regions with missing values and no estimate could be derived. ${ }^{58}$ As an alternative, we took the relative consumption, $h_{i} / \bar{h}_{i}$, as the dependent variable. Convergence is achieved. As shown in Table G.X, the truncated regression model gives a price coefficient very close to what the censored regression model does. As we exploit less information when fitting a truncation model (on about $40 \%$ of the sample), the precision is much lower. Although the coefficient on income is higher in when using a truncated regression model, this comparison gives credit to the econometric specification of the model. It gives empirical support to the theoretical discussion presented in Appendix C.2: under an assumption of stability of preferences and constant price elasticity along the demand curve, we are able identify the sample average price elasticity by using information on the individuals that locate on the left-hand side of the kink in the budget constraint.

\footnotetext{
${ }^{58}$ The maximum likelihood function of a truncated regression model is a ratio; as the algorithms behind the truncreg command in Stata use analytic derivatives, we hypothesize that the estimation failure is due to the fact that the denominator of the maximum likelihood function (the cumulative distribution function of a Normal) gets too close to zero when taking the log-relative consumption as the dependent variable.
} 
Table G.X: Consumer price elasticity estimations: comparing truncated and censored regression models.

\begin{tabular}{|c|c|c|}
\hline \multicolumn{3}{|c|}{ Dependent variable: relative consumption $(h / \bar{h})$} \\
\hline & $(1)$ & $(2)$ \\
\hline & Truncated reg. & Censored reg. \\
\hline \multirow[t]{2}{*}{ Price $(\log )$} & -0.304 & $-0.275^{* *}$ \\
\hline & $(0.449)$ & $(0.111)$ \\
\hline \multirow[t]{2}{*}{ Disposable income (log) } & $-0.076^{* * *}$ & $-0.007^{*}$ \\
\hline & $(0.027)$ & $(0.004)$ \\
\hline Observations & 4947 & 8190 \\
\hline Clusters & 28.000 & 28.000 \\
\hline
\end{tabular}

Notes: Standard errors in parentheses, clustered at the provider level; ${ }^{*}$ $p<0.10,{ }^{* *} p<0.05,{ }^{* * *} p<0.01$. Pooled data from October 2012, 2013 and 2014. Estimation of a Truncated regression model and a Tobit model by Maximum Likelihood. Specifications include as controls sociodemographic variables, dummies for the year the latest plan was decided upon, dummies for the year in which the co-payment rate was computed and year fixed effects. The dependent variable is the relative consumption, not in ratio. 